Sanz, M.A. (2019). La centralidad de la fiesta picotera en Cartagena. Revista de Antropología y Sociología: VIRAJES, 21(1). 9-58. DOI: 10.17151/rasv.2019.21.1.2

\title{
La centralidad de la fiesta picotera en Cartagena
}

\author{
MARÍA ALEJANDRA SANZ*
}

Recibido: 27 de febrero de 2019

Aprobado: 24 de mayo de 2019

Artículo de Reflexión

\footnotetext{
* Este artículo está basado en el libro Fiesta de picó: Champeta, espacio y cuerpo en Cartagena Colombia publicado en 2012 por la Editorial Universidad del Rosario. El trabajo de campo fue hecho a lo largo del año 2010 y si bien muchas cosas han mudado en el universo siempre cambiante de la champeta, especialmente con una nueva onda de popularidad alcanzada por la llamada champeta urbana en 2014, el panorama para el gremio picotero no ha mejorado y de hecho los espacios se han reducido, eso porque las dinámicas de la ciudad que describo tienden a permanecer así como los valores que las fiestas de picó intentan reivindicar.

** Maestra en Antropología social de la Universidad Federal de Río Grande del Sur. Investigadora independiente. E-mail: alesanz85@hotmail.com. (C) ORCID: 0000-0002-6522-8749. Google Scholar
} 


\title{
Resumen
}

El presente artículo pretende explicar la centralidad de la fiesta de champeta a través de su vehículo el picó en la vida de los habitantes de los barrios populares de Cartagena, Colombia. El texto a través de la descripción de diferentes elementos y actores que estructuran el mundo picotero, aborda la relación entre música y espacialidad, y analiza la forma en la que esta afecta y configura el paisaje cartagenero. De igual forma, estudia la cuestión de la corporalidad como un tipo de agencia presente en las fiestas de picó. En la conclusión, a partir de la exposición de las tensiones políticas que se presentan alrededor de la cultura picotera, se presenta la manera cómo esta estética permite la visibilización de una población marginalizada por medio de una transgresión en términos estéticos, bailables y sonoros, de espacialidades que manifiestan relaciones desiguales de poder.

Palabras clave: Cartagena, picó, champeta, espacialidad, corporalidad, fiesta.

\section{The centrality of the picotera party in Cartagena}

\begin{abstract}
This article aims to explain the centrality of the champeta parties through their vehicles called picós in the lives of the inhabitants of the popular neighborhoods of Cartagena, Colombia. The text, through the description of different elements and actors that structure the picotero world, addresses the relationship between music and spatiality, and analyzes the way in which it affects and shapes the landscape of Cartagena. Similarly, it studies the issue of corporality as a type of agency present at the picó parties. In the conclusion, from the exposition of the political tensions that arise around the picotera culture, the way in which this aesthetic allows the visibility of a marginalized population through a transgression in aesthetic, danceable and sonorous terms of spaces that manifest unequal relationships of power is introduced.
\end{abstract}

Key words: Cartagena, picó, champeta, spaces, corporality, party. 


\section{Introducción}

T a primera vez que escuché el poder del bajo de un picó fue en una calle estrecha del barrio Porvenir de Cartagena la tarde del viernes santo de 2010. El Pequeño Jr. equipado de un solo parlante y un par de brillos todos pintados de colores neón tocaba champeta, mientras sus propietarios conversaban tranquilamente en el solar de las casas. Me acerqué desprevenida y una vez presa de la onda expansiva del sonido sentí una gran dificultad para respirar. La vibración no afectaba mis oídos sino lo más profundo de mis entrañas, y mis pulmones. No sé si era por la estreches de la calle donde reverberaba el sonido, pero sentí una especie de colapso corporal que no volvió en las muchas noches de fiesta de picó que le seguirían, pero que experimentaría de nuevo un par de años después en el sambódromo de Rio de Janeiro en un festival de música funk, donde también, como en muchas otras latitudes de América Latina y el Caribe, el equipo de sonido es central. Lo que en ese momento en el barrio Porvenir me pareció demasiado intenso, se convertiría en un placer algunas horas más tarde en el toque de picós de los palenqueros y, entre más fiestas de este tipo coleccionaba, más seducida estaba por esa sensación de los bajos que afecta el cuerpo de maneras mucho más complejas que lo auditivo.

Un picó es un equipo de sonido de enormes proporciones, compuesto por uno o varios parlantes utilizados para amplificar, principalmente, música champeta. La palabra picó viene del inglés pick up, haciendo referencia o bien a la aguja del tornamesa, o a la portabilidad de estos equipos que se desplazan por la ciudad para animar fiestas barriales en las llamadas plazas o casetas. El término champeta designa a su vez un conjunto de músicas africanas y afroantillanas, así como también un estilo musical local nacido de los covers que se hacían de estas músicas venidas de otras latitudes. Estas reapropiaciones locales cantadas primero en onomatopeyas o en la lengua bantú de San Basilio de Palenque, fueron luego cantadas en español y fusionadas con músicas locales tanto tradicionales como urbanas dando como resultado la llamada champeta criolla. De la fusión entre la champeta criolla y las llamadas músicas urbanas, principalmente reguetón, dancehall, ragga y rap, nacería el hoy popular género de la champeta urbana cuyos arreglos musicales son completamente digitales.

Mi labor como investigadora en el marco del proyecto "Economías informales en la música de las ciudades de Cartagena, Barranquilla y Santa Marta en Colombia" (Botero, Ochoa y Pardo, 2011) era hacer un trabajo de tipo etnográfico sobre los circuitos económicos alternativos de los picos, 
lo que reveló una extensa y compleja red socio-cultural que me cambiaría la forma de ver la fiesta y pensar el sonido. El trabajo de campo fue realizado a lo largo del año 2010 y tuve la suerte de instalarme en el barrio El Prado, muy cerca del Mercado de Bazurto, que era uno de los epicentros del universo champetero diurno como veremos más adelante.

Deslumbrada sobre todo por el goce de estas personas en este espacio festivo, comencé a preguntarme por el lugar que ocupa la fiesta picotera en la cultura cartagenera en sus dimensiones espaciales, sociales y sensuales que no están disociadas unas de otras. Así, en el presente artículo, pretendo describir cómo se estructura la fiesta de picó en Cartagena, analizando cuáles son los factores que articulan estos eventos para finalmente intentar explicar por qué una celebración cotidiana tiene tanta centralidad en la vida de la gente que habita los barrios populares de esta ciudad. Para esto dos andamiajes teóricos principales fueron utilizados como instrumentos de análisis: la relación música-espacialidad y la relación música-corporalidad ya que en el ejercicio estético de asistir a una fiesta de picó esta tríada sonoridad-espacialidad-corporalidad está en eterna interacción como veremos a través del texto.

La idea, como propone Small (1999), es entender los actores y relaciones ideales que se establecen en esta actuación musical para comprender por qué la fiesta es tan importante dentro de las vidas de personas de clases populares cartageneras. Se trata de una suma de aspectos, culturales, económicos, socio-históricos y estéticos, acompañados por una infraestructura propia que componen lo que motiva a los champetúos a asistir cada fin de semana al picó de forma casi sagrada, para reafirmarse a través de la rumba.

La fiesta de picó no es un fenómeno aislado de las dinámicas particulares de esta ciudad, especialmente en términos de espacialidad. Ella está en constante interacción con diferentes espacialidades y, a su vez, se ve afectada por estas y las transforma. Por eso en un primer momento analizo la relación entre música y espacio, y la forma en la que estos dos elementos se construyen y afectan mutuamente, configurando lugares capaces de generar identidad y afectar el paisaje cartagenero. A continuación entro en los detalles sobre la estructura de la fiesta picotera, sus actores y elementos. En un tercer momento enfatizo la dimensión corporal dentro de este fenómeno abordando como perspectiva teórica la relación entre música y cuerpo para observar como la primera tiene el poder de afectar no solo de forma sensual el segundo sino que es capaz de imbuirlo de agencia.

Pero como no todo es fiesta en una ciudad tan desigual y segregada como Cartagena, finalmente expongo las tensiones que se presentan alrededor de la cultura picotera. La historia de la champeta es una plétora 
de prohibiciones y si esta música, sobre todo el formato de sus fiestas con el picó como corazón, resulta tan polémica, es porque el poder del picó va más allá de un potente sonido. Veremos como la estética de la puesta en escena picotera actúa como una forma de agencia al permitir la visibilización de una población normalmente invisibilizada. La fiesta de picó, más allá de ser un espacio de ocio, es capaz de actuar como una forma de subversión temporal del orden establecido, especialmente porque consigue una transgresión en términos estéticos, bailables y sonoros, de espacialidades que manifiestan relaciones desiguales de poder.

\section{Dinámicas raciales}

Después de una sinuosa historia colonial y republicana, Cartagena, La Heroica, renació como un fénix de las cenizas en las que estaba postrada hasta mediados del siglo XX, siendo hoy en día con su millón de habitantes una de las cinco ciudades más pobladas del país. En la década de 1970, Cartagena comenzó una transformación de regeneración del Centro Histórico y de las playas con énfasis en el turismo. Un proceso que se mostraría sumamente desigual, generando una segregación socio-espacial y racial. "En la transformación a un objeto de turismo, una ciudad se produce sí misma como un diseño, se produce a sí misma como un símbolo" (Krims, 2007, p. 49) $)^{1-2}$ Así se volvieron protagonistas las playas kilométricas de la Boquilla con sus exóticos pescadores, las casas coloniales y románticas del Centro Histórico, Manga y su puerto con yates, Bocagrande con rascacielos como un pequeño Miami y las palenqueras vestidas de colores vendiendo frutas tropicales. La música rescatada fue la folclórica de gaitas y tambores con los bailes que ejecutan morenos semidesnudos en las plazas de 'la ciudad vieja'; todo en una armonía de mestizaje y diversidad publicitado por las agencias de viajes (Cunin, 2003b).

Así mismo se dejaron por fuera de este producto de design, los que hoy se convirtieron en puntos disonantes de este paraíso fabricado para los gustos y los sentidos de los turistas: los vendedores ambulantes de las playas que asedian a los visitantes. Ellos son la sombra de la otra Cartagena que se resiste a desaparecer, de la Cartagena invisibilizada y champetúa en la que sus gentes han construido su propio paraíso intangible pero vivo, hecho de música y baile.

A través de la historia las pretensiones de esta ciudad han estado encaminadas a responder a las demandas eurocéntricas. Tanto así, que Jorge

\footnotetext{
${ }^{1}$ Todas las traducciones son propias.

2 "In transformation to an object of tourism, a city produces itself as a design, produces itself as a symbol".
} 
Eliecer, un vecino mío en el barrio El Prado, me explicaba cómo las mujeres blancas como yo les eran muy atractivas a los negros para "enrazar" (palabra que utilizó literalmente). Esto se debe a que el mestizaje en Colombia ha estado atravesado por la idea de un "blanqueamiento" progresivo que responde al ideal europeo (Wade, 1997b). Así, desde la colonia, una élite blanca o con pretensiones de serlo, ha buscado invisibilizar a esa mayoría de negros pobres que la han habitado y para ello una de las estrategias más efectivas ha sido la marginación espacial. Pérez y Salazar (2007) comprueban con números lo que uno como investigador cualitativo intuye: la pobreza en Cartagena es un problema grave y coincide geográficamente con un espacio marginal y un tono de piel $^{3}$.

De esta forma, lo que ven los turistas es la cara "amable" de esta ciudad, la Cartagena próspera, donde los pobres, en su mayoría afrodescendientes, han sido (re)ubicados fuera del panorama que se ofrece al visitante. Cuando los negros aparecen en esta ciudad lo hacen visiblemente como figuras exóticas comercializables o cuasi invisiblemente en las labores de servicios o en la economía informal.

Sin embargo, la champeta como música y de forma todavía más visible, en su dimensión festiva picotera, se manifiesta fuera del lugar exótico otorgado a lo negro. Así, lo champetúo es constantemente rechazado porque genera una ruptura en lo que Cunin (2003a) llama "las convenciones del evitamiento" (p. 162), es decir, el eludir la cuestión racial evitando mencionarla y evitar transgredir el lugar asignado a cada cual para contener el enfrentamiento. Para la autora, la fuerte segregación socio-espacial que caracteriza a Cartagena rara vez se expone en términos raciales o étnicos.

Además, las poblaciones negras de Cartagena están doblemente discriminadas. Por un lado por ser negros y por otra parte por no ser suficientemente negros. Sucede que en Cartagena el discurso del multiculturalismo ha amparado casi de forma única a los palenqueros ${ }^{4}$. Pero el resto de la población afro pertenece al grupo de los doblemente excluidos: por una parte debilitados de una ciudadanía efectiva por el hecho de ser negros y, por otra, del derecho de la diferencia ya que debido al discurso del mestizaje, a la presión social por el blanqueamiento y a la convención del evitamiento, les es muy difícil valerse de una identidad para defenderse (Cunin, 2003b). Es de esta población de la que hablaremos principalmente cuando me refiera a los champetúos.

\footnotetext{
${ }^{3}$ Según Pérez y Salazar (2007) “en los barrios cartageneros de mayor pobreza existe también una alta proporción de habitantes que se autorreconocen de raza negra" (p. 1).

${ }^{4}$ Habitantes originarios de San Basilio de Palenque, un pueblo fundado por los esclavos cimarrones en la época de la colonia que se desarrolló de forma más o menos aislada generando una cultura propia con marcadas influencias africanas.
} 


\section{Atlántico Negro}

Algunos de los estudios que se han hecho sobre espacialidad proponen que el espacio es una construcción social en el que la música tiene una fuerte injerencia (Leyshon, Matless \& Revill, 1995; Cohen, 1995; Hudson, 2006). En Cartagena, sus condiciones históricas y sociales como lugar han llevado a la producción de una sonoridad específica. Al mismo tiempo, esta sonoridad ha tenido una fuerte influencia a la hora de construir un lugar. Para Cohen (1995), la música no solo refleja sino que también tiene la capacidad de producir un lugar y esta producción tiene, entre otras, una importante dimensión ideológica. Así, la fiesta de picó tiene consecuencias espaciales e ideológicas sobre las relaciones entre lugar y música en Cartagena. Hablamos de una ciudad con una geografía humana compleja, una ciudad con varias ciudades delimitadas por relaciones desiguales de poder que se vuelven evidentes a la hora de hablar de música.

Debemos recordar que "la producción de lugar a través de la música es siempre un proceso político y contestatario y la música aparece implicada en las políticas de lugar, la lucha por identidad y pertenencia, poder y prestigio" (Cohen, 1995, p. 445) . La fiesta de picó es a la vez una economía con una infraestructura particular y un lugar que genera identidades al tiempo que reclama una espacialidad y cuestiona las formas de poder establecidas en Cartagena.

Al referirse al picó como un lugar, no debemos caer en la simplificación de este como un fenómeno puramente local. En el entender más clásico de los términos, espacio se refiere a lo global y lugar se refiere a lo local, frecuentemente visto de manera simplista solo como una resistencia a lo espacial dominante (Krims, 2007). Para Biddle \& Nights (2007) las naciones (entendidas como una geografía arbitrariamente delimitada que puede incluir una multiplicidad de culturas y etnias) están situadas en un lugar liminal entre lo global y lo local. Cartagena, por su parte, tiene la particularidad de situarse entre lo local y lo caribeño como estrategia de turismo. Observando el picó como lugar en medio de estas dinámicas, no puede encasillarse como únicamente local o global, de hecho las interacciones constantes entre ambas esferas es lo que le da fundamento.

No debemos olvidar que fue gracias a los picós que las clases populares de la costa caribe comenzaron a escuchar músicas venidas de otras dimensiones del llamado Atlántico Negro. Esta noción introducida

\footnotetext{
5 "The production of place through music is always a political and contested process and music has been shown to be implicated in the politics of place, the struggle for identity and belonging, power and prestige".
} 
por Gilroy (2001) remite a la imagen de los barcos de esclavos que se dislocaban por el océano generando un sistema de flujos e intercambios transnacionales. Este sistema estableció una forma de comunicación global de la cultura de diáspora más allá de las fronteras étnicas o nacionales. El picó, localizado principalmente en la costa caribe colombiana, recorre al mismo tiempo una geografía global con sus músicas traídas por encargo del Gran Caribe, Europa, Norte-América y especialmente África.

Este constante ir y venir no sólo trajo los discos de música afro de otras latitudes y a otras latitudes, sino que fue decisivo para la tecnología y la estética del universo picotero. Sin que quede muy claro cómo, los picós nacen en la década de 1950 atendiendo a la urgencia de las clases populares cartageneras y barranquilleras de amplificar una música que no se escuchaba en radios ni medios comerciales. Los parlantes eran hechos con tubos de forma artesanal y algunas décadas más tarde, serían los dueños de estos equipos los primeros en producir champetas criollas. Todos estos influjos y tensiones darían como resultado las músicas actuales, y el picó, que aparece por todo el Caribe con distintos nombres, es vehículo de esta globalización que produce un cosmopolitanismo caribeño de ciudadanías múltiples (Pardo, 2010; Contreras, 2002).

En esta vía, Stokes (2004) afirma que "la música, claramente, juega un papel activo en crear y dar forma a los espacios globales que de otra forma no hubieran ocurrido"6 (p. 67). En el caso de los picós, estas músicas a su vez fueron reforzando un sentido de lugar, de una localidad muy fuerte pero conectada con lo afro en toda su extensión diaspórica. África aparece aquí no como un origen sino como modalidad ideológica pan-africana presente en viajes circulares (Hall, 1996). Así, las relaciones entre lo externo y lo propio, lo caribeño, lo afro y lo global, han venido resignificando el espacio de la ciudad y específicamente del picó donde lo popular manifiesta toda esta globalización históricamente alimentada de forma localizada.

\section{Espacialidades múltiples}

Cartagena está dividida en tres localidades que coinciden más o menos con tres divisiones profundas, lo que la hacen una ciudad con múltiples ciudades algunas de las cuales son rechazadas o ignoradas a favor de lógicas comerciales (Paccini, 1993; Mosquera y Provanzal; 2000). Pero esta pluralidad de ciudades rechazadas ha sabido forjar una espacialidad propia que está fuertemente influenciada por el universo picotero.

\footnotetext{
${ }^{6}$ Music, clearly enough, plays an active role in creating and shaping global spaces that otherwise would not have "happened.
} 
El llamado sur-oriente es una de estas ciudades, conocido como el sector más champetúo de Cartagena. Me bastó solo un día de recorrido a pie en compañía de unos jóvenes gaiteros que habitaban en la zona para cruzar más de cuatro referentes picoteros, eso sin contar los pequeños picós guardados en los garajes o instalados en los porches de las casas de los barrios de Fredonia, El Porvenir, Playa Blanca, Puntilla, entre otras zonas consideradas "más apretás que pelo de palenquera" como decían mis acompañantes refiriéndose a lo peligrosas.

Hablar, por ejemplo, del barrio Olaya Herrera, es remitirse de inmediato al imaginario de lo que es ser champetúo: por una parte, ser un rumbero de música champeta, por otra, a un estigma social. En Olaya está la discoteca Didonky donde todos los fines de semana se monta algún picó y la discoteca Donde Fabiola a la que invitan a tocar a los DJ picoteros. Además todos los fines de semana la gente pone a sonar sus picós caseros en las calles. Olaya es pues un barrio champetúo, pero esta palabra tiene una doble connotación. Según José Quessep, productor de champeta, dependiendo de quién te lo diga y en que tono lo haga, bien puede estar volviéndote un cómplice de rumba y reconociéndote como igual, o te puede estar insultando ${ }^{7}$. Eso porque la palabra champetúo tiene un origen peyorativo del que hablaremos más adelante.

El sur-oriente está compuesto en su mayoría por barrios deprimidos que crecieron como invasiones alrededor de la Ciénaga de la Virgen. Pero tal vez esta marginalidad fue la que alentó que se generaran los picós como una forma de diversión y de catarsis. Del sur-oriente han salido picós muy importantes como el Gémini de Mr. Black, cantante, DJ y picotero que sería la cara de la nueva ola nacional que tuvo la champeta en 2014.

Pero la Ciénaga está al oriente de Cartagena y comprende muchas hectáreas de agua salina que va desde la Boquilla al norte, hasta el sur de la ciudad. Es por esto que lo que se llama sur-oriente no coincide geográficamente ya que los barrios costeros de la Ciénaga, alrededor del Cerro de la Popa, también son considerados como sur-orientales por la gente común, por ser pobres y tener una estrecha relación con los picós. La gran mayoría de estos barrios del llamado "sur-oriente" son estratos 0, 1 y 2, y tienen los mayores niveles de necesidades básicas insatisfechas y miseria, además de altas tasas de homicidio (Pérez y Salazar, 2007) que tristemente se las han adjudicado a los picós, ignorando la pobreza, segregación, marginalidad espacial y la poca infraestructura para servicios y recreación como causas más directas.

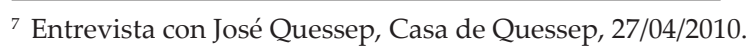


En uno de estos barrios del "sur-oriente" no geográfico conocido como San Francisco, nació y comenzó a tocar el Rey de Rocha, el picó más grande de Cartagena luego de que sus dueños inmigraran de Rocha, su pueblo natal ${ }^{8}$. En el barrio La María están las oficinas de este picó. En una visita a la sede del Rey de Rocha, tomé un taxi en la Torre del Reloj de la ciudad amurallada. Cuando le dije al conductor el destino se sorprendió y no dejó de preguntarme constantemente si sabía para dónde iba y si conocía a alguien que me recibiera en el lugar porque esos sectores eran "candela". De tomar una moto desde un barrio popular, como llegaba allí normalmente, a un taxi en la zona turística, hay una gran diferencia. Sobre todo porque en el imaginario de la gente los de la zona turística nada tienen que hacer en los sectores del sur-oriente.

Si la idea de sur-oriente se relaciona con la champeta sería un poco más preciso hablar de los barrios que quedan al oriente de la avenida Pedro de Heredia que recorre la Ciudad de norte a sur atravesando toda la geografía que no aparece en los mapas de turismo de Cartagena. Pero en barrios del occidente también hay una fuerte influencia de la champeta, especialmente en lugares como Blas de Lezo, El Bosque, Zaragocilla y San Fernando, donde hay plazas para picó, discotecas de champeta, estudios de producción de esta música, además de las casas de DJ y dueños picoteros. Resulta entonces que nos encontramos ante una Cartagena ampliamente champetúa donde lo "sur-oriental" se ha tomado el occidente y hasta sectores del norte como los barrios Canapote, Torices y Nariño.

Otro referente de la champeta que no hace parte de este "sur-oriente" es el mercado de Bazurto, la mayor plaza de mercado de Cartagena. Este lugar era en 2010 el epicentro del mundo diurno del picó. Frente al mercado, cruzando la avenida, tuve la suerte de contemplar varias veces la hoy extinta fábrica de hielo. Antes de ser demolida a finales de ese mismo año, se erguía orgullosa y colorida una pared de una bodega más alta que el resto de los locales del sector. De la mitad de la pared hasta el techo estaba cubierta de afiches gran formato dibujados a mano con colores neón y letras gordas, que anunciaban las fiestas de picó del fin de semana. La fábrica era la cartelera oficial de los eventos picoteros además de que representaba toda una estética. El Runner dice haber inventado esta usanza:

La pared de la fábrica aquella que está allá arriba yo fui el que inventé. El de la idea fui yo pa' que pegaran carteleras allá. Como ahí se bajaban los buses entonces todo el mundo se bajaba ahí y miraban pa' allá arriba, pa' la fábrica de hielo, entonces ahí es donde lo ven todos.

\footnotetext{
${ }^{8}$ Entrevista con Alberto Arias, DJ del picó Rey de Rocha. La María. 13/04/2010.
} 
Todo el mundo está pendiente de cuándo son los espectáculos y van pa' allá, miran a la fábrica de hielo porque ahí aparecen todas las carteleras de todos los bailes, todos los picós. (El Runner, comunicación personal, 07/2010)

El Runner pintaba entre los corredores de las bodegas del centro comercial El Colmenar parte del mercado de Bazurto, donde pegaba en las paredes varios pliegos de papel periódico que eran pintados a mano con témperas siguiendo un diseño premeditado. Así, cada afiche, aunque era una pieza única, parecía la fotocopia del anterior. Estos letreros artesanales son los anuncios que promocionan los eventos en diferentes partes de la ciudad con un estilo particular que hace muy fácil reconocerlos sin dudar que se trata de fiestas picoteras. También, por cada fiesta, hacían un afiche grande que pegaban en la pared de la fábrica de hielo en fondo negro y letras de colores fluorescentes.

El Colmenar es un punto de encuentro para los del gremio, pero además es un centro informal de negocios. Sentada allí esperando que pasara el tiempo pero a la vez socializando, como hacen todos los que llegan al lugar, fui conociendo todo tipo de figuras más o menos importantes del universo picotero. DJ, incluyendo a Chawala, el más famoso, DJ del picó rey de Rocha; Sonwyl Muñoz, DJ del picó el Imperio, que luego abriría su propio picó SM y también era DJ en Olímpica Stereo; dueños de picós, cantineros, dueños de discotecas interesados en toques de DJ de picós y, obviamente, los organizadores de eventos. El organizador del evento se encarga de tener, primero, un contrato con el picó y luego de arrendar un sitio. Debe sacar todos los permisos que se demoran alrededor de un mes y recorrer Cartagena de sur a norte para llenar los requisitos. Además el organizador del evento paga la publicidad tanto en afiches como en las emisoras, contacta a los cantineros, compra el hielo y paga por los refrigerios para el personal.

Este es el complejo económico y social de la champeta que se despliega en Bazurto, extendiéndose luego por toda la ciudad a través de una circulación particular y una infraestructura propia. En el circuito económico de este universo el punto de origen y de llegada es el picó. El picó produce la música que suena en las fiestas de forma exclusiva hasta que se "suelta" en el mercado. A través de la "piratería" circulan los éxitos para conseguir más adeptos que vayan a la fiesta de picó.

En Bazurto es donde trabajan los piratas encargados de la difusión de la música y, así mismo, los revendedores de compilados, volúmenes y demás producciones fonográficas. Pero hablar de piratas en este contexto es inexacto, a pesar de que es el nombre que usa la gente del medio. 
La economía en el circuito picotero es casi toda informal, excepto porque al final los artistas y productores registran los discos en SAYCO y ACINPRO. Gran parte del sistema funciona a través de tratos de palabra entre las personas. Los discos los hace un "pirata" aunque tiene toda la autorización de los dueños de los derechos de autor. "Pirata" les llaman a aquellos discos que no "son originales" plateada. Luego estos discos son distribuidos a vendedores y pronto copiados por verdaderos piratas; "soltaron un CD y salió como en tres versiones" explica Anuar Peralta, DJ del picó El Demoledor (comunicación personal, 06/04/2010).

En estos contextos donde los "originales" son cada vez más escasos y la lucha contra la piratería casi perdida, la industria musical picotera sigue funcionado a través de los canales de comercio no formales y han sabido sacarle provecho como vía de difusión y propaganda del picó y los cantantes. Así como en el caso de la tecnobrega brasilera, para la champeta la piratería es un mal necesario (Lemos y Castro, 2008) que permite la continuidad de un circuito económico y estético que tiene pocas posibilidades dentro del mercado fonográfico formal (Ochoa y Botero, 2007). Esta infraestructura paralela, donde lo legítimo y lo pirata conviven, habla no solo de la forma en la que circulan los medios en el mundo globalizado sino de la generación de estéticas propias de los grupos marginados, impulsadas en parte por la tecnología que utilizan.

Además de ser prácticamente la única vía de difusión, la piratería es la única opción de acceso a las fuentes fonográficas para personas que no tienen la capacidad económica de adquirir discos originales, que es la condición de la mayoría del público champetúo. Para Cunin (2007) la champeta ha vuelto accesible una "una cierta modernidad a una población que no se reconoce en el modelo norteamericano y andino que le ofrecen la ciudad y el país" (p. 180).

Aunque esta infraestructura se basa en la "piratería", los picoteros están en la constante búsqueda de expandir el negocio y ser reconocidos. Dado que "la piratería no es ideológica, por lo tanto no representa una conciencia política de oposición al capitalismo" (Larkin, 2004, p. 298) ${ }^{10}$. De hecho la champeta mantiene "una relación paradójica con el sistema dominante, pues depende de él para la comercialización, proceso que los subalternos buscan con fervor (en esto, la autenticidad es valiosa pero para vender el producto)" (Wade, 2009, p. 11).

\footnotetext{
${ }^{9}$ Entrevista realizada a Deberson Ríos. Estudio barrio Torices. 06/09/2010.

10 "Piracy is nonideological in that it does not represent a self-conscious political opposition to capitalism".
} 
De hecho los picoteros y los artistas buscan ser exitosos o al menos participar dentro del sistema formal e institucional, y aunque han tenido algunos golpes de suerte, la maquinaria cultural los sigue limitando a lo local. La música de los picós tampoco tiene de su lado el elemento de la autenticidad. Varios, incluso dentro del mismo mundo champetúo, han acusado a la champeta de ser una imitación barata de la música africana con una lírica pobre y vulgar. Esto no es más que un ataque en la forma de indignación estética contra un ritmo que desborda el canon convencional y que precisamente por esta característica de copiar lo africano sin remilgos de autenticidad y en la predominancia de la corporalidad explícita y la composición rítmica sobre la lírica, es que tiene contundente resonancia entre su público.

\section{Paisaje sonoro}

Además de casetas de música pirata, en el mercado de Bazurto había tiendas especializadas en champeta y música africana original, donde se conseguían los LP de antaño y CD prensados de artistas criollos. También había lugares para comprar los equipos de picó.

Bazurto abarcaba prácticamente todo el Barrio Chino. Por lo menos diez centros comerciales y veinte grandes almacenes de ropa y enseres de hogar se extendían a ambos lados de la avenida Pedro de Heredia. Además, frente a los locales oficiales del costado occidental cientos de casetas hechizas se montaban cada mañana en el andén.

Así el espacio de la calle se lo peleaban los transeúntes con las busetas. Algunas, las que tomaban la avenida Pedro Romero hacia el suroriente, tenían que meterse obligadas por este carril caótico y permanecían casi quietas, deslizándose lentamente hasta por media hora, mientras atravesaban las cuadras del mercado. Lo que se oía era bastante particular, pitos permanentemente, los gritos de los vendedores promocionando su mercancía y los de los sparrings de las busetas (los ayudantes del conductor que cobran el pasaje) que anunciaban su destino. Además, en cada tres o cuatro de estas casetas había un lugar con música y un televisor con video que por lo general presentaba accidentes espectaculares y toreros corneados. La mayoría de lo que sonaba durante este recorrido por entre las casetas que dan a la Pedro de Heredia era champeta, aunque también algunos reggaetones, rancheras y vallenatos.

Pero este beat de la champeta que después de un tiempo se vuelve inconfundible sonando a todo volumen y a veces coincidiendo con el de la música de los radios de las busetas, el tono de los pitos y el coro de los gritos en un concierto disonante, parece que dictara el ritmo de todo el mercado. 
Se trata de un soundscape (paisaje sonoro) construido por una serie de prácticas sociales, políticas e ideológicas, que a su vez afecta estas relaciones.

El paisaje sonoro es en alguna forma análogo al paisaje terrestre, en la medida que contiene todo a lo que el oído está expuesto en una determinada locación sónica. Así como el paisaje terrestre, el término contiene fuerzas contradictorias de lo natural y lo cultural, lo fortuito y lo compuesto, lo improvisado y lo producido deliberadamente ${ }^{11}$. (Samuels, Meintjes, Ochoa \& Porcella, 2010, p. 330)

Así Cartagena en general y Bazurto de forma concentrada, están comprendidos en un paisaje geográfico enteramente atravesado por una cultura del sonido que ha sido determinante en la transformación del espacio físico. "Respecto al ruido ambiental (...) hace al paisaje sonoro cotidiano expresivo de valores culturales" (Leyshon et al., 1995, p. 424) ${ }^{12}$ y los ruidos del mercado son expresivos de valores altamente champetúos, que por lo tanto no entran dentro de las convenciones de la ciudad postal. Como Cunin (2003a) resumió: “El mercado reúne los obstáculos y las contradicciones de la ciudad, de esta Cartagena popular y desordenada, que la Cartagena turística e internacional quisiera borrar del mapa" (p. 292). De allí que Bazurto no aparezca en el mapa de Colombia es Pasión ${ }^{13}$ y que haya un plan de re-reubicación (ya había sido desplazado de Getsemaní) en lugar de uno de revitalización (que se hace urgente), ubicándolo en un terreno al lado del terminal de transportes, lejos, muy lejos, de la zona turística.

De hecho la misma palabra champetúa es definitoria de un paisaje sonoro. Se refiere a la música, pero también a un ritmo que está en los cuerpos de las personas, en su forma de moverse, de mirar y de hablar, así como también hace referencia a un nivel sociocultural de forma peyorativa. Cunin (2007) explica:

La asociación, presentada como evidente, entre el "negro" y la música, es una mezcla de naturalización de la cultura y de referencia a un África inventado, que reconoce al otro asignándole al mismo tiempo un lugar circunscrito y un estatuto inferior, relegándolo a la periferia geográfica y cultural de la nación colombiana. (p. 178)

\footnotetext{
11 "Soundscape was somewhat analogous to landscape, insofar as it attempted to contain everything that the ear was exposed to in a given sonic setting. Like "landscape," as well, the term contains the contradictory forces of the natural and the cultural, the fortuitous and the composed, the improvised and the deliberately produced".

12 "Discussing environmental noise (...) makes the everyday soundscape expressive of cultural values".

${ }^{13}$ Mapas turísticos distribuidos gratuitamente que son realizados por la Marca Colombia.
} 
Así, este paisaje sonoro champetúo construye una espacialidad física de marginalidad en la que vive una mayoría negra.

Pero no solo los barrios populares y el mercado son champeta. También en los barrios nobles encontré rastros champetúos. En Manga, sobre la vía principal de la isla, están los estudios de Olímpica Stereo que tiene programas de champeta. En Manga también está la casa de Francisco Manjón, dueño del picó $E l$ Conde. Según él, esta casa es la muestra de que El Conde fue un buen negocio en otro tiempo ya que gracias a las ganancias del picó la consiguió en un sector tan bueno como lo es Manga.

Hoy en día los picoteros no pueden darse ese tipo de lujos. Los dueños de los equipos han invertido muchos millones de pesos en decenas de parlantes, complejos equipos de luces, torres de sonido, consolas, una tarima, máquinas de humo y, sin embargo, en la ciudad es difícil ver los picós sonando completos. El problema es que en Cartagena cada vez quedan menos plazas como las de antaño y en 2010 una de las pocas que sobrevivían era Chambacú. Se trataba del área del Parque del Manglar, sobre la avenida Pedro de Heredia, antes del puente que comunica el Centro Histórico con el resto de la ciudad. Chambacú fue hasta 1970 un barrio miserable, inspiración de la novela "Chambacú, Corral de Negros" de Manuel Zapata Olivella. Este barrio fue erradicado y para sus habitantes esta decisión significó la negación de la cara negra de Cartagena. En su lugar quedó un espacio vacío pero, a pesar de la remoción de Chambacú, los negros dejaron en este lugar uno de los templos de su fiesta.

Aproximadamente cada mes este parqueadero abierto era cercado por los cuatro lados con vallas de zinc para delimitar el espacio de la fiesta. En la pared opuesta a la entrada armaban el picó en todo su esplendor acogiendo miles de personas. Pero desde que construyeron un centro comercial al lado de la plaza, los toques en el lugar son escasos. Esta no es la primera ni la última vez que desplazaron lo champetúo de las inmediaciones del centro y de la Cartagena turística. Con la plaza de la Boquilla, otro de los pocos lugares donde un picó puede sonar completo, ocurre algo similar. Megaproyectos de condominios estrato seis se están desarrollando en la zona, y los pescadores han venido vendiendo sus lotes a la orilla del mar, muchos presionados por la valorización de la tierra y la subida del costo de los servicios públicos. Lo que ocurre con esta lucha espacial es de corte político.

Así, a pesar de lo movido que es el universo picotero en Cartagena, donde no existe un fin de semana (excepto si hay ley seca) sin que desde el jueves hasta el lunes haya toques de picó, es difícil ver un equipo armado completo. La falta de espacios abiertos hace que muchos de los picós más grandes toquen fuera de la ciudad durante el fin de semana para 
regresar el lunes, en el mejor de los casos, a tocar a medio armar en alguna discoteca cartagenera.

Pasacaballos, Tierra Bomba, Santarosa, La Boquilla, Bayunca, Santa Ana, Roldán, entre otros, son algunos de los poblados rurales donde se organizan fiestas a las que van los picós de Cartagena, para tocar con todo el esplendor de sus equipos, con cierta regularidad. En los pueblos existe un público picotero fiel y masivo, con un rango de edades mucho más amplio que en la ciudad. Tienen la ventaja de ser más flexibles en las regulaciones para los picós y por lo general la fiesta va hasta más tarde, además de que existen espacios al aire libre para los toques (el cielo es el límite para armar el picó, no el techo como en los lugares cerrados).

Pero al hablar de la dimensión rural del universo picotero, la primera referencia geográfica es San Basilio de Palenque dado que fueron los palenqueros los primeros en hacer champeta criolla. El grupo Anne Swing, heredero de los sextetos que animaban las fiestas hasta mediados del siglo pasado, grabó las primeras canciones en onomatopeyas y luego en su lengua palenquera. De ese grupo pionero saldrían cantantes de la importancia de Charles King, Melchor y por supuesto Viviano torres, su vocalista original.

Así, el universo picotero es ampliamente extendido no solo en Cartagena sino a través de toda la Costa Caribe colombiana. No es un fenómeno aislado, pequeño y exótico como muchos medios intentan hacer creer. Funciona de manera paralela a la ciudad debatiéndose entre el deseo de formalizarse y ser reconocidos y la practicidad de su propia infraestructura en buena parte al margen del marco institucional.

Esta economía extendida por la ciudad es una fuente de empoderamiento y una de las razones por las cuales las fiestas de picó son tan importantes para la gente cartagenera. No obstante, es solo la más básica porque esta infraestructura picotera reproduce un orden lógico y una estética con alcances profundos, que da cuenta del contexto en el que se yergue.

En Cartagena el sonido de los champetúos, tan característico, va marcando una espacialidad tanto global como local, inserta en medio de una serie de intercambios sonoros con otras latitudes caribeñas y africanas, así como con una localidad muy fuerte. Bazurto y Chambacú son lugares que cuentan las historias de un paisaje sonoro. El picó, tanto los grandes y famosos como los que suenan en los porches de las casas del "sur-oriente", es el vehículo de este paisaje que a través de su amplificación define una frontera simbólica generando una serie de espacios con características muy propias que condensan una identidad particular. Si se entiende que las "identidades son multidimensionales, constantemente renegociadas, pero 
nunca divorciadas del lugar" (Connel \& Gibson, 2003, p. 281) ${ }^{14}$, entendemos por qué los picós no son simplemente máquinas que animan una fiesta popular sino los protagonistas de un universo estético capaz de construir un sentido de lugar propio en una ciudad excluyente.

Se trata de un paisaje sonoro contenido en un espacio físico, geográfico y simbólico en una serie de lugares y personas, muchas de las cuales viven de este mundo o se expresan a través de esta estética. Caminos, paredes, estilos que continúan extendiéndose en todas las latitudes de esta ciudad, o de la Otra: de la que queda fuera de la postal.

\section{El evento}

Asistir a una fiesta de picó es una experiencia sensorial bastante demandante a la que curiosamente me acostumbré con facilidad. Casi siempre se pasan varias horas de pie, porque en muy pocas plazas (lugares para toques de picó) hay mesas y sillas, además de estar soportando el golpe de los bajos y los muchos decibeles de sonido en los oídos, por la misma cantidad de tiempo.

Debe también tenerse en cuenta que en un toque de picó siempre se está rodeado de varios cientos, e incluso miles de personas en un espacio que puede ser cerrado, con poca ventilación y muy caliente. Cuando el espacio es abierto, como en Chambacú, la brisa del mar se encarga de acariciar los cuerpos refrescándolos placenteramente. Pero como vimos, son pocas las plazas abiertas que quedan en la ciudad. Luego hay lugares como el Didonky y el club de amigos de Blas de Lezo que son cerrados pero con un techo de zinc sobre unas columnas, permitiendo que entre algo de aire por el espacio que existe entre estas columnas y las paredes del lugar. Pero otra cosa es cuando el picó toca en una discoteca cerrada con el techo a escasos tres metros de altura.

Recuerdo el toque del picó El Imperio en la discoteca Mar Azul. Había por lo menos cuatrocientas personas en un espacio de unos 40 metros cuadrados sin ventanas. El efecto del aire acondicionado era nulo a pesar de su tamaño, y en cambio aportaba una humedad que se condensaba en las paredes y en los cuerpos. Entre mejor fuera la canción más la euforia y mayores los grados de temperatura. Los cuerpos se movían en masa. La ropa de todos estaba empapada en sudor. Un solo sudor que escurría de los rostros en pesadas gotas. Con pañuelos, muchos y muchas secaban su cara y seguían bailando, pero era una tarea inútil. Cuando salí de la fiesta parecía como si me hubiera metido a nadar con ropa.

\footnotetext{
14 "Identities are multidimensional, constantly being renegotiated, but never divorced from place".
} 
La mejor forma de soportar una fiesta de estas es bailando, y es que no están pensadas para nada más. Así, una vez se empieza a gozar el baile y a entender las dinámicas, el tiempo pasa mucho más rápido y sin darte cuenta, comprendes la particularidad de los picós y el porqué han sobrevivido a pesar de sus enemigos públicos durante tantas décadas.

Para Leyshon et al. (1995) "el reconocimiento de los placeres de la música debe ser central para cualquier entendimiento de su poder" $(\text { p. } 424)^{15}$. Sin duda, el poder más evidente del picó radica en su capacidad de producir placer en sus asistentes. Un placer musical, rítmico, corpóreo, que además no encuentran en ninguna otra parte, no sólo porque no tienen acceso económico y social a otros escenarios sino porque lo que pasa en un picó es muy diferente a lo que ofrece cualquier otra escena.

En estos lugares hay una intimidad muy estrecha entre los asistentes que comparten la historia de una cultura y de una ciudad con unos procesos de mestizaje particulares atravesados por marcadas desigualdades. A través de la fiesta de picó se establece una comunidad que no es cerrada y de hecho permite una alta circulación de personas con distintas trayectorias sociales que comparten en un ambiente claramente urbano e imbuido en los influjos de la globalización. Estas características fluidas entre lo local y lo global permiten pensar en la fiesta de picó bajo el término de escena como lo define Straw (2002):

Para aquellos que estudian la música popular, "escena" tiene la capacidad de desligar los fenómenos de unidades más rígidas y teóricamente problemáticas como clase o subcultura (incluso cuando ampara la promesa de una eventual rearticulación). Al mismo tiempo, "escena" parece ser capaz de evocar ambos, la calidez de la intimidad de una comunidad y el fluido cosmopolitanismo de la vida urbana. Esto añade un cierto dinamismo a la primera, y el reconocimiento de círculos internos e historias de peso que dan un sentido de orden secreto a la fluida superficie del segundo. (p. 7)

Así el evento picotero es una escena que permite a los asistentes compartir una estética específica que a la vez que genera un sentido de

\footnotetext{
15 "... a recognition of the pleasures of music must be central to any understanding of its power".

16 "For those who study popular music, "scene" has the capacity to disengage phenomena from the more fixed and theoretically troubled unities of class or subculture (even when it holds out the promise of their eventual rearticulation.) At the same time, "scene" seems able to evoke both the cozy intimacy of community and the fluid cosmopolitanism of urban life. To the former, it adds a sense of dynamism; to the latter, a recognition of the inner circles and weighty histories which give each seemingly fluid surface a secret order".
} 
comunidad, soporta sin mayores contratiempos los flujos de una ciudad cosmopolita como lo es Cartagena.

\section{Rupturas y aproximaciones}

Un momento determinante en la historia picotera es cuando se comenzaron a producir champetas locales. Anteriormente la música que sonaba en los picós se conseguía a través de amigos y conocidos de los picoteros que vivían en el exterior, encargados de traer o mandar música africana de Europa o directamente del Africa. Pero ante la dificultad en términos logísticos de conseguir discos exóticos y mantenerlos como exclusivos ${ }^{17}$ especialmente con la llegada del internet, se comenzaron a producir las primeras champetas locales, bautizadas criollas.

Fueron los palenqueros los primeros en hacer covers de los éxitos de antaño, primero imitando los dialectos africanos con onomatopeyas, después componiendo letras en el tipo de lengua bantú que se habla en San Basilio y, finalmente en español. Fue solo cuestión de tiempo y de la contingencia para que en 1993 El Rey de Rocha produjera la primera champeta con el objetivo exclusivo de ser tocada en el picó, cantada por el palenquero Hernán Hernández. El proceso se revirtió y primero fue éxito en el picó y después como disco. Desde entonces la criolla compite con la africana y los picós se dividieron, llamándose salseros los que no producen música, sino que siguen trabajando con discos exclusivos de música africana y afrocaribeña. ${ }^{18}$ Aquellos picós que producen sus canciones de champeta criolla con cantantes locales son los que se conocen como picós de champeta. Los exclusivos son entonces hoy en día éxitos que el mismo picó produce para su repertorio.

El llamado salsero es el picó que se armaba con cajas de parlantes artesanales hoy reemplazados por bajos industriales. El picó salsero pone música africana y afrocaribeña que consigue a través de encomiendas o que baja de internet. De hecho es poca la salsa que se oye. Los toques salseros son normalmente duelos o piques, donde se enfrentan dos o más equipos. Cada uno coloca tres canciones para luego cederle el turno a su rival. El ganador es aquel que logre prender más la fiesta y el que tenga discos exclusivos más exitosos. Las parejas bailan con las piernas entrecruzadas muy cerca, abrazados. Los movimientos lentos y cadenciosos, los pasos

\footnotetext{
${ }^{17}$ Los exclusivos eran canciones exitosas en las fiestas, pertenecientes a un solo picó. Los nombres de las canciones y cantantes se matenían en secreto, arrancando los sellos y escondiendo las carátulas. Esto garantiza la fidelidad del público que para oír estas piezas no tiene otra opción que ir a bailar a un picó determinado.

${ }^{18}$ Entrevista con Alberto Arias. Sede Rey de Rocha, La María.13/04/2010.
} 
pequeños. Fue el picó salsero el que estableció que la champeta se baila "en una sola baldosa", y aunque le sobra sensualidad, no es un baile explícitamente sexual. Ocasionalmente los hombres hacen solos de baile para lucirse, moviendo los pies de manera muy rápida y haciendo pequeños saltos. El público que está compuesto principalmente por personas entre los 40 y los 70 años de edad y todo en este picó está revestido de cierta nostalgia, especialmente porque quedan ya muy pocos picós salseros que puedan contar la historia.

Por su parte, el picó de Champeta tiene gran fuerza. La primera vez que vi un toque de picó de este tipo fue en Chambacú con el Rey de Rocha, el picó más grande de Cartagena sonando frente a un público de más de 3 mil personas entre los 18 y los 40 años. El Rey estaba armado completo, con 16 bajos, 24 medios y 16 brillos montados sobre una estructura metálica que se elevaba unos seis metros. En la mitad de dos torres de sonido estaba la tarima donde toca el DJ, además de pantallas de plasma, láser y luces. La euforia de la gente era impresionante, solo comparable con la euforia del público que presencia un concierto en vivo. La estrella es el DJ y todos miran hacia la tarima. La gente cantaba las canciones, gritaba y saltaba. Cuando se les calentaban las cervezas regaban lo restante dando círculos con la muñeca por encima de las cabezas, salpicando a todas las personas alrededor. En pocas horas todos estábamos bañados en cerveza y nadie se preocupaba por el hecho.

Un tercer tipo de picó apareció en Cartagena en la última década. El picó de dansal nacido de la influencia del dance-hall jamaiquino traído por la colonia sanadresana residente en la heroica. ${ }^{19} \mathrm{El}$ primero en montar un picó de dance-hall fue Víctor Julio Sabalsa, DJ y dueño del picó que lleva su nombre y que anima fiestas con música jamaiquina y sanandresana, más al estilo de los antiguos picós, coleccionando canciones de otras geografías. Pero fue Deberson Ríos, conocido como DJ Dever, el primero que produjo dansal para su picó el Passa-Passa Sound System. Así como la champeta fue la imitación de la música africana, el dansal se caracteriza por ser una versión criolla del dance-hall jamaiquino. Los passa-passistas son jóvenes entre los 15 y los 25 años de edad, aunque sería injusto ignorar a los niños entre los 8 y los 15 años que van a las rumbas-sanas con DJ Dever y bailan y gozan tanto como los más grandes, pero sin tomarse una gota de alcohol. El picó es pues la escena sonora para tres de las más influyentes músicas populares cartageneras. "De forma paralela al concepto de paisaje sonoro está el de 'escena sonora' una representación tridimensional de un espacio del que emerge el performance" Moylan (como se citó en Samuels et al.,

${ }^{19}$ Entrevista realizada a Junior Boombastik, CC. La castellana. 26/04/2010 
2010, p. 337). ${ }^{20}$ En esta escena se observan las diferencias más importantes entre estos tres géneros -que recaen en los actores más que en las máquinasque van más allá de los estilos musicales.

Estas evoluciones musicales alrededor del picó responden a unas demandas de mercado por una parte, pero al mismo tiempo son la muestra de una circulación musical a nivel del gran Caribe de forma inmediata, así como con África todavía vigentes. Tanto en el producción de la champeta criolla como en la del dansal que se hace de forma totalmente digital, es frecuente la utilización de discos que fueron éxitos en los picós salseros para la elaboración de las pistas, mezclados con ritmos más pop, e incluso elementos del folclor tradicional como gaitas y tambores. Se trata de un proceso de hibridación de estilos y, "en cualquier encuentro de tipos musicales no hay nunca encuentros simplemente inocentes o casuales libres de la operación de la ideología" (Biddle \& Nights, 2007, p. 13) ${ }^{21}$. La aparición del dansal nos habla de procesos de cosmopolitanismo de una nueva generación que se reafirma a través de nuevas estéticas, sin olvidar del todo sus raíces.

Tal vez por este fondo ideológico propio de la hibridación, la división entre picós y la aparición de la champeta criolla generó un quiebre en la convención del evitamiento. En el momento en que la champeta deja de ser la música africana, vista con recelo pero aún exótica, y comienza a ser producida localmente usando el español como lengua (lo que además implica cobrar voz de forma explícita) la aproximación simbólica de esta nueva propuesta es percibida como particularmente amenazante.

\begin{abstract}
Al transformarse en champeta adquiere no solo una dimensión local, sino que es la alteridad cercana e inquietante y se estigmatiza como "la música de los negros" racial y socialmente. Se establece así una asociación directa, en la representación colectiva entre la música, la violencia y las poblaciones negras (Cunin, 2003b, pp. 378-379)
\end{abstract}

En la introducción del libro: Segregación y diferencia en la ciudad, Carman, Vieira y Segura (2013) explican cómo frente a la fragmentación creciente de las ciudades latino-americanas "los sectores populares son considerados

\footnotetext{
20 "Thus running parallel to the concept of the soundscape is that of the "sound stage" a threedimensional representation of a space from which performance emerges" (Moylan 2002).

21 "(...) we must also inflect the notion of hybridity in order to be able to recognize the power relations at work in this mixing of styles here: in any encounter of musical types, there are never simply evenhanded or playful encounters free from the operations of ideology. On the contrary, what is at work here, it seems to us, is the complex and contested encounter of a music seeking to re-regionalize itself with a more generalizing (perhaps, even globalizing) musical style".
} 
más contaminantes o impuros cuanto más próximos se encuentran a áreas de prestigio, o dicho de otro modo, cuando violan lo que es el principio de máxima intrusión socialmente aceptable" (p.17). Eso porque la proximidad genera un miedo de contagio, de mezclarse y de perder la propia identidad por parte del grupo dominante en relación al excluido. La generación del estigma de violencia que carga la champeta y especialmente el picó como lugar, incrementó con la aparición de la champeta criolla operando como forma de defensa de los grupos dominantes, inquietos, sobre todo por la propiedad contagiosa de estos ritmos y sus corporalidades.

\section{Sobre cobas y placas}

Los DJ son figuras de suma importancia en el mundo picotero. No solo hacen parte de la farándula criolla (Contreras, 2008) sino que tienen la responsabilidad de animar la fiesta y hacer bailar a las personas lo que implica un conocimiento particular y una combinación de varios elementos, entre esos lo que se dice en el micrófono. La primera vez que fui al Rey de Rocha no entendía nada de lo que decían las letras de las canciones ni el DJ. Charles King me traducía lo que iba diciendo el DJ Chawala y me explicaba lo que significaban muchas expresiones. El no ser capaz de entender también tiene que ver con la incapacidad de escuchar con nitidez a tantos decibeles, pero luego, poco a poco y sin darme cuenta me fui entrenando en el costeñol y en el picóléxico, en la carga simbólica de muchas expresiones y en identificar las palabras dentro de la saturación del sonido.

Además de lo dicho en vivo existen las placas. La noche del cumpleaños de Sonwyl Muñoz, el picó El Imperio que tocaba en la discoteca Didonky estrenó una canción del cantante Twister. Cuando la fiesta ya estaba en furor elDJ 'suelta las placas' que dicen: "exclusivo, no lo tiene nadie" y "me atrevo a decir que va a ser un éxito seguro". Las placas son grabaciones hechas a la manera de cuñas publicitarias para el picó y es una cuestión de prestigio que la voz usada sea la de "Mike Char", Miguel Char Algarra, dueño de Olímpica Stereo. Es tal la importancia de que las placas sean grabadas con su peculiar voz que toda una industria pirata se ha desprendido de esta tradición, hay quienes se encargan de imitar la voz del locutor y muchos otros utilizan las placas ya existentes para editar placas nuevas y vendérselas a picós emergentes que no son amigos de este personaje.

Desde el principio de los picós se utilizaron las placas, antes grabadas por Jairo Paba para marcar los exclusivos y así evitar que algún espía del público los grabara en vivo y se los entregara a la competencia. “¡El Conde! ¡El sentimiento de un pueblo!" proclaman las placas del picó El Conde en medio de las canciones. Una segunda función de las placas es engrandecer 
el picó, y una tercera es avivar la competencia en los duelos. “Está bien que seas indio, pero no puerco. Te voy a coger y a bañar con música brava y exclusiva para que aprendas a respetar" decía una de las placas del Sabor Estéreo en el pique salsero contra El Guajiro (representado por un indio "tira flechas").

La técnica del DJ para pegar un éxito es la repetición. Pero es todo un arte saber hacerlo, implica técnica, carisma y saber la medida para que la repetición no lleve al aburrimiento del público sino a su euforia. La canción nueva la ponen entera la primera vez. La segunda vez empieza el trabajo sicomotriz: el DJ pone los diez primeros segundos, la retroceden y la vuelven a poner esta vez durante treinta segundos. Retrocede de nuevo y la deja sonar un minuto hasta el coro. El DJ canta el coro y lo retrocede y lo vuelve a poner, no sé cuántas veces, hasta que incluso yo puedo cantar el estribillo. Más tarde cuando ponen de nuevo la canción la gente la reconoce con facilidad y comienza a bailarla. Una misma canción suena varias veces en una noche en el picó, tanto si es nueva como si ya es un éxito.

Este procedimiento tiene explicación en que a través de la repetición la música puede arraigarse en el cuerpo, distinguiéndose con sus movimientos de la experiencia cotidiana (Cohen, 1995). La repetición busca una incorporación para llevar al cuerpo a bailar y a que el espectador experimente algo especial que solo vive dentro de la escena picotera. Además de las características de la puesta en escena, lo que se oye en las fiestas es diferente a lo que estaba grabado, definiendo un paisaje sonoro particular contenido en el picó como lugar determinado. Es pues, la escena sonora que se vuelve tridimensional no solo en la propuesta performática sino en los cuerpos que la habitan.

Este talento de los DJ de "pegar" una canción, sumado a la constante producción musical, hace que las piezas tengan un ciclo de vida muy corto. Estando en Cartagena vi canciones que se estrenaron en una noche y que a mi siguiente visita quince días más tarde eran un éxito rotundo esperado con ansias por la gente. Por esta misma vía, una canción pegada durante un mes y medio ya es considerada vieja.

Aparte de hacer uso de las placas, del canto y de la repetición de las canciones, hay otra herramienta para animar al público: las cobas.

La coba es lo que llaman ustedes el saludo, o sea decir: bueno esto va para mi compadre Raúl. Es la coba para Raúl. ¡Gózala compadre Kevin! ¡Gózala! Esa es la coba. La famosa coba. Hoy en día en el picó la coba es como el 70 \% de la animación. Porque hay seguidores que si no los saludan no van. Hay unos que dicen que no son seguidores sino que son coberos, al que lo saludan van, al que no lo saludan no van. 
A mí me gusta tal disc-jockey porque ese es el que me saluda (Wilson Muñoz, comunicación personal, 30/07/2010)

Las cobas se hacen en vivo generalmente en las parte de la canción que no llevan letra, y son agradecimientos a los colaboradores y reconocimientos a la fidelidad de los seguidores. Es una cuestión de prestigio la que hay detrás de las cobas, ser saludado por un DJ, un personaje admirado por la gente, delante de cientos de personas. Cuando a una persona del público se le hace una coba, normalmente brinda, o alza la mano, haciendo notar que se trata de ella. Incluso hay gente que es invitada a subir a la tarima y se le entrega el micrófono para que haga sus propias cobas que generalmente están dirigidas a la calidad de la rumba del picó o a los DJ. Este es el máximo reconocimiento que puede hacérsele a un seguidor en una fiesta. Así, otra de las particularidades de los picós estriba en ser espacios donde la reafirmación de una identidad normalmente marginada se transforma en fuente de status social.

\section{Musicar}

El arte de la puesta en escena picotera se encuentra en lograr que los cuerpos entren en el baile, es decir, generarles la necesidad de movimiento, y esto implica la suma de varias características en un orden determinado. DeNora (2004) explica cómo la efectividad musical sobre el cuerpo no es una causa necesaria de lo sonoro sino que está medida por otros factores:

El punto aquí es que la música no solo actúa en el cuerpo. Sus efectos son el resultado de mucho trabajo orientado a adaptar el material musical al estilo del movimiento (...) es siempre hacia y a través de las formas en la que es apropiada, que la música proporciona recursos estructurantes- dispositivos que permiten y constriñen el cuerpo. ${ }^{22}$ (DeNora, 2004, p. 96)

La fiesta de picó es la suma de factores no solo auditivos sino también visuales (como la presencia de la máquina y la disposición de la plaza), materiales (como el hecho de que haya una cantina) y sociales. Cuando

\footnotetext{
22 "The point here is that music does not just act on the body. Its effects are the result of a lot of work oriented to fitting musical material to movement style.... Thus, to say that music will 'cause' things to happen, that it makes the body do things or that its objective properties will automatically entrain the body in particular ways, is to miss the collaborative dimension of how music's effectiveness is achieved, for it is always in and through the ways that it is appropriated that music provides structuring resources - devices that enable and constrain the body. Music provides environmental materials that may be used in ways that 'afford' different bodily capacities".
} 
falla algún ingrediente de esta receta se "cae" el evento, porque la gente no se anima a bailar, ni consume una cantidad de licor significativa en términos monetarios.

En la puesta en escena picotera al lado del DJ principal está el DJ segundo, que hace las veces de telonero. También está el baterista, pianista o tecladista, que cumple la función de hacer una serie de efectos de sonido sobre las canciones. Cada una de las teclas del teclado electrónico del baterista corresponde bien sea algún tipo de tambor o a alarmas, pitos, rugidos, ladridos, explosiones de bomba y toda una colección de sonidos sampleados, que incluso llevan cobas.

A estos efectos de sonido hechos en vivo se les llama perreo. La función del perreo es acentuar la percusión y llevar la cadencia del baile durante toda la canción, especialmente y cobrando protagonismo durante el "espeluque", que es el clímax de la pieza musical. La intervención del baterista ha cobrado un valor estético muy importante en el universo picotero, y es una de las grandes diferencias entre la música que se escucha en un disco o por la radio, y la que se oye en vivo en el picó. Se trata de la generación de piezas únicas e irrepetibles que solo son grabadas en el caso de los volúmenes.

Un volumen, es la compilación de exclusivos de un picó en un CD o DVD, pero este volumen tiene la particularidad de imitar un toque en vivo. Cuando sale un volumen sale en perreo, esto quiere decir que incluye placas, cobas y efectos de sonido hechos por el baterista. Esto garantiza que el exclusivo siga siendo del picó y que quede claro a quién pertenecen las piezas hasta que se decida entregarlo en limpio al mercado, es decir, con las canciones tal cual salen del estudio.

En la fiesta de entrega del volumen 3 del picó El Chulo de Moda, en Pasacaballos, tuve el honor de ser invitada a subir a la tarima y saludar por el micrófono del DJ. Pero hablar por un micrófono en el picó implica saber el dialecto, las palabras adecuadas con un peso simbólico que logran poner en furor al público. El resultado fue un público perplejo que me nos miraba como si no entendiera ni siquiera el idioma.

Eso porque la gente que asiste a una fiesta de picó comparte una visión de mundo que depende de unos códigos de conducta, de una estética, una sonoridad, y una cantidad de simbolismo que yo no compartía completamente. Y es que:

Tomar parte en una actuación musical es tomar parte en un ritual cuyas relaciones reflejan, y nos permiten explorar y celebrar, las relaciones de nuestro mundo como imaginamos que son y que deben ser. Sin embargo, no nos bastará cualquier actuación. Solo bastan 
actuaciones en las que nosotros, los participantes, podemos explorar, afirmar y celebrar las relaciones de nuestro mundo. (Small, 1999)

Esta es una de las razones por la cuales la fiesta de picó es tan central: no se trata de cualquier actuación musical sino de la celebración de las relaciones del mundo champetúo que refleja en gran parte lo que implica ser cartagenero de clase popular.

El público picotero cartagenero es exigente en términos musicales $y$ es en el momento en el que decide bailar que aprueba una canción. Mientras no le guste permanecerá quieto. El extremo opuesto es la euforia, el público deja de bailar y empieza a brincar, a cantar a gritos y a mover las manos hacia el cielo, como queriendo romper el aire. La música es pues decisiva para un picó y esto viene de la mano de la exclusividad. Un elemento que ha perdurado en los picós desde el principio es esta idea. Un buen picó se caracteriza por poner a sonar música que solo se puede escuchar en sus fiestas. La exclusividad de música es lo que ha hecho que existan seguidores de picós: grupos de fanáticos fieles a su máquina que se desplazan por la ciudad para asistir a los toques.

El público vuelve a un picó por la rumba, por lo que pueda divertirse, bailar, desfogar y por sentir la euforia colectiva. Sin embargo

Al conjugar las actividades de consumo del baile y la música, la discoteca articula la noción de identidad social incorporada a la conspicua y diferencial exhibición del gusto. Como tal, sirve para distribuir explícitamente conocimientos y formas de capital cultural a través de vectores como el género, la raza y la clase. (Straw, 1991, p. 380) ${ }^{23}$

Por esto, ir a una fiesta de picó no solo es gozarse la vida, se trata también de frecuentar un círculo social, de reafirmar un orden donde la clase, raza y género tiene unas significaciones, de encontrarse con la misma gente, de ser reconocido y de sentirse parte de algo.

Estas relaciones son la verdadera sustancia de la actuación musical contenida en la fiesta picotera. Para Small (1999) hacer parte de una actuación musical se define con un verbo: musicar. Al musicar se crea un conjunto de relaciones no solo entre los sonidos sino también entre las personas que participan en este y también en relación con el mundo externo al espacio de esta actuación musical. El ejercicio de musicar en el picó es entonces el

\footnotetext{
23 "Bringing together the activities of dance and musical consumption, the dance club articulates the sense of social identity as embodied to the conspicuous and differential display of taste. As such, it serves to render explicit the distribution of knowledges and forms of cultural capital across the vectors of gender, race and class".
} 
reflejo de un mundo mucho más amplio y aporta a este en la medida que es el lugar en el que se refuerzan vínculos sociales y culturales. Más allá de su música estridente y difícilmente confundible, los actores comparten unas representaciones de mundo que excede las paredes de la plaza. Entre estas el valor de la inclusión y el acceso a una forma de expresión dentro de una ciudad altamente segregadora. Wade (1997a) explica como:

Juntarse en núcleos y crear pequeños espacios de relaciones densamente entrelazadas dentro de la totalidad de la red étnica -que después de todo se expande mucho más allá de estos núcleoses un recurso para la construcción de una defensa para el propio ser negro y para la creación de otro pequeño mundo en el cual ser negro es de nuevo el estado normal de las cosas (...) también es un anhelo por reclamar un espacio cultural en la ciudad (...) donde se pueda definir la moralidad y la conducta social por medio de sus propios procesos sociales. (p. 322)

Entendemos como el evento picotero se configura como un núcleo de defensa de los cartageneros de las clases populares, más allá de si se consideran o no negros, en el que ser champetúo deja de ser un estigma para convertirse en un lugar de reivindicación, identificación y autoafirmación social, con importantes resonancias étnicas.

De esta forma, los picós más que ser espacios para la recreación de los habitantes de los barrios populares de Cartagena, se han convertido en un medio para la valoración y el reconocimiento de lo negro en la ciudad, además de reforzar y redefinir territorialidades urbanas. (Bohórquez, 2000, p. 3)

Si bien a los picós no solo asiste gente negra, lo africano si tiene una predominancia. De hecho para Contreras (2008) la gente asiste a los picós para reencontrarse conscientemente con África.

Sin embargo, para Birembaum (2005) en Cartagena "la lógica de una estética popular es más bien una apropiación de los símbolos y significados de la cultura dominante para recontextualizarlos dentro de un esquema estético muy propio" (p. 206). Birembaum reconoce que este esquema estético está fuertemente influenciado por la raza, dado que "es a través de una identidad cultural popular y afrosincrética que se vive la pobreza y la marginalidad de la clase popular". No obstante, para el autor no debe escencializarse lo popular como negro (aunque en Cartagena coincida altamente) ya que se trata de "identidades actuadas y no destinos biológicos". 
Por mi parte considero que si bien la champeta hace mucho superó los límites raciales para volverse una estética popular e híbrida, ignorar el componente racial que pervive alrededor de estas músicas puede ser tan peligroso como escencializarlo. Para Gilroy (2001) “al dejar para atrás el esencialismo racial por ver 'raza' en sí misma como una construcción social y cultural, esta ha sido insuficientemente consciente del poder de resistencia de formas específicamente racializadas de poder y subordinación" (p. 87). Así, más allá de cómo se identifiquen racialmente los propios actores del universo picotero, no debe olvidarse que desde las clases dominantes los champetúos son constantemente racializados. Una reapropiación de estos elementos que remiten a lo afro dentro de la champeta funcionan como una forma de agencia y de resistencia, no necesariamente consciente, contra esquemas muy viejos de dominación.

Queda claro que la gente a la que le gusta la champeta, la africana y el dansal, reconoce ya como un saber popular los origines negros de estas músicas, aunque en la práctica se trate de construcciones compartidas que exceden los límites de una africanidad estricta. Tal vez más justo sería la idea de pan-africanidad diaspórica que utiliza Hall (1996) para pensar el lugar de lo negro en el universo de la champeta.

La fiesta de picó, sea mediante su componente étnico o social, genera de todas formas un núcleo de defensa de una estética y de autoreconocimiento como champetúo, más allá de su tono de piel. Estas características permiten la creación de un sentido de comunidad en la medida que dentro del espacio picotero se deconstruyen los órdenes sociales con los que deben vivir sus asistentes en el espacio cotidiano de la ciudad. Lily Kong explica cómo la música tiene la propiedad de generar un sentido de communitas en el que "los individuos son temporalmente liberados de sus roles jerárquicos y de los estatus que generalmente llevan" (Kong, 1995, p. 195), ${ }^{24}$ creando un lugar de unidad e igualdad. Si el picó es tan importante es también porque es uno de los escasos espacios de diversión inclusivos en Cartagena, y en este se afianzan unos lazos estéticos que mantienen las relaciones de una buena parte de la clase popular y la forma en la que esta da significado al mundo.

\footnotetext{
24 “Turner's (1974) notion of communitas, discussed in the context of pilgrimages, may be applied here. Turner argues that pilgrimage results in the abrogation of social structure, a state in which individuals are temporarily freed of the hierarchical roles and statuses that they ordinarily bear. Instead, there is a condition of unmediated and egalitarian association between individuals. The space thus created is a site of unity and equality. Music too can have that effect".
} 


\section{Música y cuerpo}

Sin baile no hay fiesta y sin fiesta no hay picó. El cuerpo está en medio de estas relaciones estéticas, tanto sonoras como de movimientos danzantes. Esto se entiende porque la música es un factor construido socialmente que hace parte del medio ambiente, y el cuerpo está constantemente influenciado por este ambiente.

El cuerpo por su parte, a la vez que es un medio importante de expresión y el vehículo físico de comunicación del individuo con el mundo, es también la manifestación de unos procesos sociales y políticos y ha sido educado a través de unos ideales culturales (Lock \& Farquhar, 2007; DeNora, 2004) por medio, en gran parte, de ejercicios estéticos. Dentro de estos procesos el baile es fundamental como herramienta para aprehender el mundo y en el universo del picó el baile es la manera de expresión más importante y el fin último de toda la fiesta.

En la fiesta de picó, los diferentes elementos que la componen están organizados para generar placer estético en sus asistentes a través del baile. Para Quintero (2009) el baile es una forma africana de aliviar el dolor, sentimiento que se presenta de manera latente en la ciudad de Cartagena dados sus niveles de pobreza, desigualdad y violencia. Ya Viviano Torres dejaba claro que el nombre "terapia", que trataron de darle a la champeta para hacerla más comercial, se refería en realidad al baile y no a la música ${ }^{25}$. Así mismo, para Hudson (2006) y DeNora (2004), la música corporeizada tiene propiedades terapéuticas y, además, coinciden con Meintjes (2004) en que el baile puede ser una fuente de empoderamiento.

La fiesta de picó en Cartagena tiene un carácter subversivo que sienten sus opositores. Este poder se debe en gran parte a la forma de bailar, sobre todo, porque es la expresividad de una sensualidad condensada. De hecho, asistir a un evento de este tipo es un ejercicio casi que exclusivamente sensual. Recuerdo vivamente la experiencia de perderse en medio del furor de la fiesta, de dejar lo racional para fundirse en medio del sudor que se restregaban las parejas cachete contra cachete, pecho contra pecho, sumado a las cervezas derramadas por los aires que hacían todo muy húmedo y caliente. Esta intimidad hace parte de la sensualidad del baile y es una condición de todas las fiestas de picó. Desaparecen las barreras corporales y el público comienza a parecer una gran masa palpitante al unísono, desdibujándose la individualidad.

\footnotetext{
${ }^{25}$ Entrevista con Viviano Torres, oficina de Viviano, edificio Comodoro. 31/03/2010.
} 
Los movimientos del baile en el evento picotero tienen la capacidad de incorporar no sólo el paisaje sonoro sino el físico: incorporar el picó como lugar, entiendo lugar en todas sus dimensiones.

Los lugares pueden ser literalmente incorporados (...) los sensuales y expresivos movimientos de la danza, pueden ser particularmente memorables e intensos. Todo puede tener un profundo impacto en la memoria individual y colectiva y en las experiencias de lugar, y sobre las emociones e identidades asociadas con lugar. (Cohen, 1995, p. 443)

Así, es el baile el que permite de forma más efectiva que el lugar del picó se incorpore a través de una memoria física intensa. Un éxito musical, que como veíamos es lo que la gente exige para calificar un picó como bueno y para volverse seguidor de este, se determina porque a la gente le gusta bailarlo. Un éxito es tal porque la gente se "espeluca" cuando escucha la canción, entregándose por completo al baile. Es por esto que al que va a una fiesta de picó se le llama bailador.

En cada uno de los tres tipos de picós que hay en Cartagena: el salsero, el de champeta y el de dansal, los bailadores tienen diferentes formas de moverse, pero si hay algo común en la forma de bailar de los tres tipos de fiesta es que se baila en el puesto, no hay desplazamientos, ni cuando se baila solo ni cuando se está bailando de parejas. Eso, exceptuando los solos de baile, que son cada vez más escasos en Cartagena y es posibles verlos casi que exclusivamente en los picós salseros.

En el picó salsero las parejas bailan toda la pieza juntos y lo más importante es el abrazo. Hombre y mujer juntan sus cuerpos desde el pecho entrecruzando las piernas rodeando al compañero con los brazos sin que parezca muy importante de qué parte se agarren mientras estén cerca.

En los picós de champeta la mayor parte del tiempo se baila solo mirando al picó. Cuando bailan en pareja no duran necesariamente toda la canción pegados. Así, bailan algunos fragmentos de la canción uno frente al otro pero separados y luego cuando sube la intensidad del perreo, juntan los cuerpos. Él se acerca con las piernas abiertas, remangándose un poco el pantalón para estar más cómodo y ella se acomoda en el medio con las piernas juntas. Las pelvis y el vientre de ambos quedan pegados pero las espaldas se arquean un poco de tal forma que el pecho se separa del

\footnotetext{
26 "In this sense, places can be seen to be literally embodied. Through their bodies and bodily movements (whether through long-distance travel, walking or conversation), people experience their environment physically. (...) the sensual and expressive movements of dance can be particularly memorable or intense. All can have a deep impact upon individual and collective memory and experiences of place, and upon emotions and identities associated with place".
} 
de la pareja. Los movimientos que recorren ambas caderas juntas, en tal coordinación que bien pareciera una, comprenden todas las posibilidades de dirección y ritmos. Las parejas casi nunca se miraban a los ojos, en parte debido a la dificultad que representa el estar tan cerca. Mejilla contra mejilla las cabezas apuntan hacia abajo al lugar de encuentro de los dos cuerpos que bailan. También es común que la mujer baile de espalda al hombre y este junte su pelvis al trasero de ella. Existe no obstante una excepción a la regla de las pelvis juntas. Se trata de "el choquecito" o "choque-choque" separando y "chocando" las pelvis en una imitación literal del acto sexual.

Mientras en el "choquecito" de champeta las parejas no se despegan más de diez centímetros, en el dansal pueden separarse alrededor de unos treinta centímetros antes de volver a encontrar sus pelvis con mucha más fuerza. Así es todo en este baile, mucho más grande, mucho más gráfico. La razón es porque gran parte de estos jóvenes han aprendido lo que saben, por supuesto de la champeta, pero también de los videos sobre dance-hall que ven por internet.

Si bien la forma de bailar cambia dependiendo del tipo de picó, todos tienen una misma raíz que puede rastrearse en la forma de bailar de los viejos. Se trata de "el baile "mulato", policéntrico o descentrado, [que] espacializó una estructura sentimental alternativa. Este tipo de alternativas indirectamente vendrían a representar brechas democratizadas anticoloniales en el terreno de la hegemonía" (Quintero, 2009, p. 57). $\mathrm{Y}$ es este el camino por el que ha avanzado el germen picotero. Este baile descentrado se opone a las lógicas de un solo principio vector típico del pensamiento ilustrado heredado de los europeos que opera aún como dominante.

Dentro de los procesos de mestizaje, tan supremamente desiguales, la música ha sido un terreno ganado por lo afrosincrético (Small, 1999) que ha configurado nuevas corporalidades dancísticas mucho más explícitas en términos sexuales con ritmos mundialmente aceptados como el reggaetón y el pop. Sin embargo, la forma de bailar que se usa en los picós sigue escandalizando a gran parte de la cultura hegemónica local y nacional, lo que puede deberse a dimensiones ideológicas con las que se ha asignado la música de los picós, específicamente la champeta.

Preguntándole a la gente respecto a la dimensión sexual del baile, lo que más se obtienen son risas maliciosas, especialmente cuando hablan del "choquecito". Muchas de las letras de champeta más exitosas tienen juegos de palabras de doble sentido, por supuesto apelando a lo sexual. También, claro está, la champeta está cargada de denuncia social y letras sobre el amor y el desamor, lo que haría ligero clasificar esta música como únicamente sexual. En el dansal, las referencias a la sexualidad en las letras 
son completamente explícitas, lo que parece ir de la mano con una forma de bailar más gráfica y con la irreverencia de los más jóvenes.

Para Cunin (2003a) “es, sin duda alguna, en su evocación directa y a menudo sonora de la sexualidad que los textos de la champeta manifiestan su poder subversivo y su carga social de manera más directa" (p. 284). Debido a este carácter subversivo, uno de los aspectos más criticados por los opositores sobre esta música son letras. Sin embargo, esto tiene origen en una forma estética heredada por generaciones dónde prima lo sonoro sobre lo lírico. Esta es una característica de las músicas de la diáspora, nacida de grupos humanos esclavizados que hablaban diferentes lenguas pero que establecieron lo rítmico y lo corporal para comunicarse y establecer identidades (Gilroy, 2001; Quintero, 2009).

Así, en este tipo de ritmos pensados para bailar, el contenido y profundidad de las letras es lo de menos. Los champetúos (entre los que incluyo a los que bailan dansal, aunque muchos de ellos podrían tener objeciones) son muy conscientes de lo empapada en sexualidad que está la fiesta picotera. La diferencia radical es que ni les parece vulgar ni se escandalizan. Es un comportamiento normalizado en sus cuerpos a través de muchas generaciones, y es posible ver a niños muy pequeños bailando champeta como los mayores, sin mayor morbo.

La gente se está divirtiendo, se está expresando en su cultura altamente sexual y está usando la fiesta y el baile como una forma de catarsis social. Niber García es champetúo de la vieja guardia y define el baile de champeta como cadencioso:

Cadencioso, o sea el movimiento (...) Mamita, pa' aclararte más el término, la cadencia consiste...o sea, eso es como un golpeteo de cintura, eso es como cuando uno ve una muchacha que tiene la barriguita afuera y tiene el estómago planitico' así, y baila con esa cadencia así que se mueve pa' allá y pa' acá, o sea, lo atrae a uno. Ya tú lo que quieres es llegar y moverte al compás de ella. Al ritmo cadencioso. ¡Eso es cheverísimo!. (Niber García, comunicación personal, 13/04/2010)

Así, lo champetúo es una forma de moverse, no solo de bailar, también de caminar, de estar y de ver la vida, que define el disfrute, en gran parte sexual.

Por supuesto hay quienes piensan que este tipo de baile es vulgar, pervertidor e incluso satánico, y muchos otros adjetivos que pueden verse 
en los comentarios de la gente por Internet ${ }^{27}$ que definen lo mucho que escandaliza este tipo de fiestas y de bailes a la mayoría de gente que no es público picotero. Además, muchas de estas personas piensan que la forma de bailar esta música, al invitar tan directamente a la sexualidad, tiene la culpa de tantos embarazos en adolescentes en Cartagena. Pero en una sociedad tan machista y con pocas posibilidades de proyección social, el baile puede ser el último de los peldaños que contribuyen a este problema.

Tal vez los verdaderos motivos que se esconden tras tanto repudio se hallan en que:

En la historia de la música occidental, la subversión de la autoridad y la seducción por medio del cuerpo han sido dos amenazas constantes para los sectores hegemónicos. Para esta autora (McClary) lo político de la música se encuentra en la forma en la que se relaciona con el cuerpo, y desestabiliza las convenciones socialmente aceptadas de género, subjetividad y sexualidad. (Bohórquez, 2000, p. 8)

Esta íntima relación entre música y cuerpo que existe en el mundo de la champeta es vista por los opositores como amenazante. Por un lado porque es la manifestación de una cultura que históricamente ha tratado de invisibilizarse. Por otra parte porque esta cultura con sus bailes "obscenos" es altamente tentadora, encarnando así unas características morales asociadas con el pecado sexual. Para Hall (1996), "esta "visión” del lugar del Otro, por asî decirlo, nos sitúa no solamente en su violencia, hostilidad y agresión, sino también en la ambivalencia de su deseo" (p. 358).

Sin embargo, debe tenerse cuidado con naturalizaciones que hablan de una condición sensual-sexual del negro expresadas a través del baile. Bailar es un ejercicio cultural construido y no corresponde por naturaleza a ninguna raza. Nash (2000) explica cómo estas asociaciones sobre la música y un ritmo "natural" frecuentemente racializado, han desorientado las políticas públicas culturales. Que el tambor sea una herencia africana predominante en los picós y que a través del baile haya una catarsis que involucre aspectos sensuales muy marcados, no significa que el champetúo sea necesariamente negro, sexual y naturalmente bailarín. Por esta misma vía, Quintero (2009) afirma:

\footnotetext{
${ }^{27}$ En YouTube hay un video colgado por papili2 titulado "champeta baile satánico y pervertidor" (sic) que es una nota periodística sobre la forma de bailar champeta. El usuario comenta a continuación: "mara derrumbar más la moral baile para abrir más la mente hacia el sexo depravado no hay cosa ke se haga ke no haiga sexo de por medio" (errores textuales).
} 
(...) el baile caribeño se presenta, pues, como una desenfrenada sensualidad irreflexiva. Quisiera, por el contrario, argumentar que la naturaleza transgresora comunicativa de sus músicas y danzas se ubica precisamente en el intento de romper -en sus zigzagueantes definiciones de humanidad, espiritualidad y ciudadanía- con esa dicotomía conceptual (cuerpo-mente). (p. 52)

Esta dicotomía tiene su origen en el pensamiento ilustrado donde los binarismos establecieron el orden esencial del pensamiento europeo. Sin embargo, en la cultura popular del renacimiento existía la noción de cuerpo grotesco que hacía énfasis en las partes de comunicación abierta al mundo exterior, un cuerpo penetrado o proyectado hacia afuera, un cuerpo permeable en oposición al cuerpo moderno individual (Bakhtin, 1993). Ese cuerpo grotesco pertenece al mundo de lo "bajo "en oposición a lo "alto" y para Stallybrass y White (1986):

La cultura dominante construye a esos excluidos en términos del cuerpo grotesco. Lo "grotesco" aquí designa a lo marginal, lo bajo, lo que queda excluido desde la perspectiva de un cuerpo clásico que si está situado en alto, dentro y en el centro es precisamente en virtud de todo lo que excluye. (p. 33)

La corporalidad picotera exhibe con énfasis ese bajo corporal con sus movimientos y letras sexuales, con sus fiestas y especialmente en el espeluque como veremos a continuación, donde se pierde la individualidad. Por eso son consideradas de mal gusto y para la cultura dominante cartagenera se trata de otra moral, una desviada. En efecto, lo que está en juego son valores explícitos en el baile, incorporados a través de la música. "La música puede ser un medio a través del cual los grupos subordinados negocian o se oponen al sistema simbólico dominante" (Kong, 1995, p. 189)28 y como en estos ritmos lo melódico y lo corporal no se encuentran divididos, esa corporalidad exacerbada choca con lo simbólico dominante, generando una molestia en el campo visual, una tentación en el plano sensual y una vergüenza ajena.

Así, el poder subversivo de la música picotera no se encuentra en un discurso determinado, ni en la reivindicación política de las negritudes. Su poder está en gran parte en el baile que rompe un orden de corporalidad y pensamiento: el champetúo disfruta del picó y de bailar en este, porque es una forma de expresión cultural con la que se siente identificado, que responde a otras lógicas epistemológicas. No debemos olvidar que el baile

\footnotetext{
28 "Music can be a means through which subordinate groups negotiate or oppose the dominant meaning system".
} 
tiene la capacidad de manifestar expresividades corporales que hablan de la relación con el entorno material y cultural (DeNora, 2004), pero que no pueden explicarse fácilmente con palabras. De hecho, existe un desorden inherente al baile y al sonido dentro de las fiestas picoteras, que lo hace muy difícil de controlar (Cunin, 2003a) y es justamente en esta condición que excede los límites cuantificables, ordenables y controlables, donde reside el poder de la danza (Nash, 2000). En la champeta este desorden bailable está pensado desde la propia composición de las canciones, como veremos a continuación.

\section{El "espeluque"}

Las canciones de champeta criolla y dansal tienen un elemento esencial para la fiesta: el "espeluque". Es un pedazo de la canción donde predomina la percusión, se omite la melodía completamente y tiene un estribillo que la gente se aprende con facilidad. En él la voz es igualmente percusiva y es cantada prácticamente sin variar el tono.

La canción viene en armonía, en una armonía y entonces cuando viene el espeluque quitan el bajo de la canción y queda solo la percusión. [Se le dice así] porque es el pedacito donde la gente se espeluca (...) hubo un tiempo cuando se le inventó el nombre del espeluque era por eso. El disco salía y no bailaban, no agarraban a la pareja hasta que no llegara el pedacito ese (...) entonces ya el disk-jockey como sabía, uno pone el pedacito ese, no lo pone desde el comienzo sino ya donde va a llegar el espeluque. (Wilson Muñoz, DJ del picó El Imperio, comunicación personal, 07/04/2010)

No hay que confundir el espeluque con el coro. Las canciones de champeta tienen su coro melódico y se vuelve fácil predecir el momento en el que "viene el espeluque", bien sea porque es introducido literalmente, o porque lo preceden expresiones como "súbele, súbele, súbele" o "viene, viene, viene" o "que se pega, se pega, se pega", entre otras. En el picó mientras suena el espeluque, el baterista que ha permanecido haciendo efectos de perreo durante toda la canción enfatiza su labor y el DJ anima a la gente con más fuerza cantando a todo pulmón el estribillo, sin poder evitar bailarlo junto con el público.

El efecto de todo esto es que la gente se pone como loca, los que no agarran a la pareja para hacer el famoso "choquecito" saltan, botan la cerveza al aire y gritan el estribillo de tal forma que toda fiesta se despeina, sin duda de ahí su nombre. El espeluque es el momento de más euforia de una canción y el público lo espera con ansias para dar rienda suelta a lo que su cuerpo 
quiera expresar a través del baile. Nash (2000) explica como la danza tiene la capacidad de liberar el cuerpo de las ataduras cotidianas y llevarlo a un estado desenfrenado, a "perderse a "sí mismo" en el movimiento" (p. 656). ${ }^{29}$

Cuando hablaba de lo exigente que puede llegar a ser una fiesta de picó me refería a esto, a lo que implica liberar el cuerpo de las barreras sociales y entregarlo al disfrute del baile, del calor, del roce, de la caricia, del sudor y de los aromas. Calcular sin mucha mente y con más intuición la posición de los brazos, la empatía en los movimientos, la dosis de cercanía y la de alejamiento. Las parejas hablan muy poco, aún si se están conociendo, porque es tal el grado en el que sienten la música y el baile que una conversación banal los sacaría de este éxtasis en el que se concentran.

Es el baile el fin último de toda la industria picotera y el espeluque su clímax. Espeluque es la expresión dialectal local para la palabra "despelucarse", despeinarse y "en ese momento fiesta y desorden se vuelven sinónimos" (Cunin, 2003a, p. 282). Para Quintero (2009) este desorden está presente en la música mulata, por ejemplo, en la síncopa o en el "montuno" del son cubano. Y este "desorden" -que en realidad lo es sólo por diferenciarse a la métrica eurocéntrica- por lo general bailable, trasciende lo sonoro.

El poder de los picós, asociado a una corporalidad y sonoridad específicas, tiene su explicación en que remite a un sentido de identidad y pertenencia con el lugar, registrando afectivamente valores e ideas (Cohen, 1995; Meintjes, 2004). La centralidad de la fiesta de picós en Cartagena se debe también a que estas fiestas condensan una manera de llevar el cuerpo, de sentir y representar el mundo a través de la música y el baile, aspectos no disociados de un solo y complejo musicar.

\section{La máquina}

En el estudio de Rafael Puentes varios cantantes y picoteros discuten de dónde viene la palabra picó. Algunos opinan que de "peeks", la marca de unas agujas para vinilo muy famosa que se utilizó durante décadas en los picós más viejos, antes de la tecnología del CD que está siendo reemplazada ahora por el MP3. Charles King dice que picó es el nombre que se le daba a todo equipo hecho de manera artesanal, y que de ahí quedó. El ahijado de Pacho Manjón (dueño de El Conde), Edwin Polo, confirma la versión de los intelectuales que han escrito sobre el fenómeno: la palabra picó viene de "pick up", en inglés, levantar; algo que puede moverse. Un picó es entonces una discoteca ambulante, un equipo de sonido de gigantescas

\footnotetext{
29 "to lose 'oneself' in the motion".
} 
proporciones que se mueve, se instala en diferentes partes de la ciudad, y suena durante varias horas con música exclusiva con muchos decibeles de volumen (Contreras, 2008; Muñoz, 2002; Martínez, 2003).

El picó hoy en día es un sistema de sonido complejo y totalmente tecnologizado. Sin embargo, si se retoma la idea del "pick up" y si se considera que los picós más gigantescos logran ser transportados, cualquier máquina que reproduzca sonido con gran potencia merece este nombre en Cartagena. Así, el picó tiene la capacidad de moverse sin importar su tamaño. Esta característica refuerza la idea de una máquina corporeizada, vehículo físico de una sonoridad almática, como el cuerpo lo es de un espíritu.

Un picó es entonces un equipo de sonido de grandes parlantes. Por esta razón, cuando le preguntaba a Namy Way, productor de videos de champeta, cuántos picós había en la ciudad su respuesta fue tan diciente: "Puede haber por lo menos 800 picós porque hay uno casa de por medio" (Namy Way, comunicación personal, 12/05/2010). Estos pequeños picós caseros, que son grandes en comparación con el equipo de sonido que se compra en una tienda de cadena, constan de por lo menos uno o dos parlantes de alrededor un metro de altura. Estos picós no tienen un fin comercial. Se ponen a sonar en las terrazas de las casas los fines de semana solo por el placer de oírlos y de exhibirlos, o para animar fiestas familiares o de barrio.

Para Small (1999) “el concepto de paisaje sonoro está en sí mismo anclado en una forma de escucha que solo se vuelve posible a través del desarrollo de formas tecnológicas de mediación y grabación" ${ }^{30}$ y el picó se ha vuelto la forma predilecta de expresión de esta cultura, asemejándose a una extensión fálica de su orgulloso dueño, merecedora de atención, cuidado y portadora de un poder reproductivo: el de crear un paisaje sonoro, una estética tecnofílica, como dice Birembaum (2005).

Los picós son mimados como niños, cultivados como plantas, tratados como seres vivos. Tienen nombres y apodos, amigos y enemigos. Tienen personalidad y caprichos. Al final los picós son tan corporeizados que son humanizados, mascotas maquínicas para el disfrute corporal de sus amos, que nacen, crecen, reproducen música y, como ha sido la suerte de muchos, mueren, quedando sus restos empolvados en algún garaje. Esta dimensión antropomorfa vuelve al picó un miembro más de la familia. Por esta razón no es de extrañarse que muchos negocios picoteros sean familiares, manejados principalmente por hombres. No en vano Nevis Quintero afirmaba que "el picó es su vida", sintiendo la ausencia de su máquina, extensión de su propio cuerpo, un cuerpo social.

30 "The concept of soundscape is itself anchored in a form of listening that only became possible through the development of technological forms of mediation and recording". 
Esto se debe a que un picó es un centro de socialización muy importante, se cobre o no boleta. Tener un buen picó implica en esa medida estatus social, que los vecinos, los amigos o incluso los desconocidos admiren la máquina, disfruten la música y decidan allí hacer su rumba. Que un picó se vuelva un negocio es bastante difícil, de allí que la mayoría de sus dinámicas barriales sean públicas.

\section{El "meke" en el cuerpo}

Un picó no es una fiesta cualquiera, su encanto, según los seguidores y los mismos picoteros, es sentir la música, y no solo auditiva o emocionalmente, sino sentirla físicamente en el cuerpo. La gente que va un picó está ansiosa por sentir "el meke", "el golpetazo", el "mondagazo", o "el fresco" (refiriéndose a la onda que se siente como viento). Me explican que un "meke" es un puño, dicho de forma coloquial término adoptado de los barranquilleros que define en lo que todos estamos de acuerdo: un golpe. En lo musical, como un terreno sensual, lo sonoro y lo táctil no se encuentran disociados, se trata de ondas que producen vibraciones más allá de lo audible (DeNora, 2004). Significa entonces que el público busca sentir el bajo en las entrañas, sentir el golpe que produce la vibración de una frecuencia tan baja. Ese golpe es lo que rige la fiesta: el golpe del tambor, el golpe de los bajos y el golpe marcado en el baile con las caderas, los brazos y los saltos cuando llega la euforia. Eso sin mencionar "el choquecito" que es un golpeteo de los cuerpos, uno contra otro.

El meke es una de las razones principales por las cuales la máquina es tan importante. Es lo que diferencia un picó de cualquier otro equipo de sonido. Si un buen picó se distingue de uno regular es por su potencia y la capacidad de generar esta sensación en el cuerpo de los bailadores que parece hacer olvidar los problemas hipnotizando con una frecuencia que solo da paso al goce. El meke genera en el espectador un respeto hacia la imponencia de la máquina y deja claro que se trata de una fiesta: ese impacto en el cuerpo tiene como fin empujar al baile y, como diría Namy Way, te hace bailar aunque no te muevas ${ }^{31}$.

No hay forma de hablar de un picó sin hablar del meke. Es algo que está presente en las conversaciones de la gente cada que se menciona este tipo de fiestas. Javier Acosta, ingeniero de sonido de El Rey de Rocha, explica:

(...) El bailador es exigente y a él le gusta por ejemplo con determinado sonido, por ejemplo los bajos. Los bajos le gustan tan exagerados que

\footnotetext{
${ }^{31}$ Conferencia dictada en la universidad Central, septiembre 29 de 2010.
} 
la presión acústica le remueve el cuerpo, la ropa se te mueve, ya. (...) Que no sé cómo hace el bailador, en la parte delantera eso tan lleno, como haces para soportar esos bajos que a veces tú no puedes ni respirar. (...) pero no se puede manejar mucha potencia hacia afuera porque perjudica también a los vecinos (...) hay sitios dónde no se puede llevar el equipo. En el caso de Chambacú, cuando lo ponemos mirando hacia Bocagrande, eso no dura diez minutos, que está bastante lejos desde Chambacú, allá a los edificios de Bocagrande, allá se activan las alarmas de los carros, con la frecuencia de los bajos, porque tenemos cabinas especiales (...). Tú sabes que viene la gente desde afuera a descansar, a donde no haya bulla, a donde haya tranquilidad, y nosotros a poner esos equipos como si fuera un terremoto. Ellos se quejan enseguida y toca aminorar la potencia. (Javier Acosta, comunicación personal, 13/04/2010)

El meke de los picós, esta potencia que retumba es uno de los factores que más molestan a sus enemigos y que interrumpe continuamente el proyecto turístico de la ciudad. Esta musicalidad estridente es vista como una provocación por parte de las élites, especialmente porque "los champetúos hacen escuchar a toda la ciudad el recital de sus picós, también conocidos como 'tumbatechos'” (Cunin, 2003a, p. 285), imagen que remite a la potencia de la vibración sonora. Las tensiones entre lo que la cultura hegemónica considera una musicalidad "correcta" y las expresiones festivas populares retumbando a todo volumen y de forma indiscriminada por toda la ciudad, generan una lucha por el paisaje sonoro en la cual los picós toman la delantera. Por eso mismo cada vez son más restringidos los toques en términos de horarios y espacios para las fiestas. Pero desde que se les permita sonar, el meke del pico se vuelve dominante no solo en lo sonoro sino en lo táctil y vibratorio.

Martín Leal, DJ del Picó Salsa de Puerto Rico de Barranquilla dice:

Para mí la diferencia de los picó de ahora es que no le camina el sonido. Y en cambio anteriormente la máquina de tubos sí. Porque aquí estaba sonando un picó y eso se sentía allá en la cárcel ¡lejos! En cambio ahora no, la máquina de transistores el sonido es ahí mismo, aquí mismo. En el estadero, aquí mismo. No le camina, para mí. Por eso es que nosotros no hemos decidido hacer máquinas de las nuevas. ${ }^{32}$

Esa imagen del sonido que camina muestra claramente que la potencia del volumen, tan problemática en términos ambientales, contiene

\footnotetext{
${ }^{32}$ Sabroso! A road trip to Colombia's Caribbean coast. Disponible en línea en https://www.youtube. com/watch?v=0RzwcBxoiKg.
} 
una intención espacial transgresora. Se trata de la capacidad de estas músicas de colonizar el paisaje sonoro de las ciudades más allá de las fronteras espaciales que impone el orden establecido, lo que tiene fuertes implicaciones simbólicas.

El protagonismo de la percusión "es el bajo profundo de todos los ritmos y movimientos corporales. Ésta era, y es, el "África” que "está vivita y coleando en la diáspora" (Hall, 1996, p. 356), y que se ve reflejada en varios aspectos de la estética picotera: en el meke de forma literal, en el baile simbólicamente, en el cuerpo vibratoriamente y el remplazo de lo lirico por lo percutivo en la composición de las canciones. Además es una postura política inconsciente fácilmente visible en Cartagena desde los tiempos de la colonia, "al cabildo picotero de la verbena y a su tribu de bailadores, la congrega el tambor electrónico sublimado etnotecnológicamente en el picó" (Contreras, 2002, p. 7). Este tambor electrónico convoca a un grupo de personas que comparten una identidad, tiene ciertas propiedades adictivas $\mathrm{y}$, sobre todo, una forma de agencia que se manifiesta en el alcance sonorovibratorio que logra imponiéndose espacialmente.

ParaKong(1995)lamúsica tienealcancesintangibles peroidentificables muy difíciles de contener. Para ella, esa propiedad de lo sonoro genera una falta de control sobre lo que se escucha, así nuestra configuración del mundo está altamente impactada por la música de formas que no somos capaces de reconocer. Por eso los alcances sonoros de los picós exceden el campo ambiental para posicionarse en una lucha por la configuración de mundos. La música de los picós invade los espacios aislados y diseñados para lo comercial de la Cartagena turística, alterando la percepción de estos y afirmando una comprensión del mundo diferente.

Esta sonoridad estridente e inconfundible, difícil de controlar, traspasa las fronteras simbólicas y espaciales que una ciudad segregada como Cartagena intenta imponer para marcar un orden espacial, racial y de clase. El bajo del picó capaz de recorrer kilómetros y penetrar paredes conquistando espacios a los que las propias personas que originan estos sonidos son restrictas, es un discurso en sí mismo. Es la voz de una población continuamente invisibilizada y el picó es vehículo difusor más efectivo de este sonido subversivo. La fiesta de picó es celebración contra el sufrimiento y su poder sonoro está contenido en la máquina, que además aparece como una extensión del cuerpo imbuida en agencia y sublevación.

\section{Estigmas efectivos}

La mayoría de las fiestas de picó a las que fui acabaron con la presencia de la policía. Solo dos de ellas porque hubo peleas, muchas porque la fiesta 
había continuado después de la hora límite del permiso, pero también varias veces porque la policía decidió apagar el picó sin ninguna razón legal aparente: quejas de los vecinos por el ruido o porque decidieron confiscar las motos de los asistentes, todo esto aun cuando los toques tenían los trece permisos necesarios para hacer un evento. El público siempre partía de los toques con una mezcla de frustración y resignación.

Las fiestas de picó tienen una cantidad importante de enemigos públicos y privados. Por una parte hay un problema de contaminación auditiva que afecta a los vecinos de las plazas que se quejan contantemente de no poder "pegar el ojo" en toda la noche. Pero por otra, existen una serie de imaginarios y de estigmas sociales complejos. El más fuerte y recurrente es la asociación de los picós con violencia, estigma muy efectivo que ha justificado una serie de decretos prohibitorios que se suman a una lista de varias décadas de persecución. Para Charles King, cantante de champeta: "Sacan unos decretos supuestamente por violencia y ayer hubo una guerra de pandillas. Más bien eso es discriminación cultural" (Charles King, comunicación personal, 09/09/2010) y tiene razón. Este tipo de decretos alimentan una larga historia de censuras a las fiestas populares afrosincrénticas (Muñoz, 2002) que se deben a que en Cartagena los ideales de mestizaje con los que se promociona la ciudad en realidad remiten a ideas de homogenización y de una pretensión de blanqueamiento que obedece a la lógica jerárquica colonial, aún vigente, evidente en la persistencia del racismo y la desigualdad económica (Wade, 1997a; Connel \& Gibson, 2003).

La extensa tradición discriminatoria hacia la champeta comienza desde su mismo nombre. La idea de llamar "champetúa" a la gente que escuchaba música de la diáspora africana vino de las reducidas clases altas cartageneras. Champeta es un machete desgastado que termina siendo usado en la $\operatorname{cocina}^{33}$, especialmente por los vendedores de pescado del

\footnotetext{
${ }^{33} \mathrm{El}$ término champeta es evidentemente una palabra africana que nace desde los palenques del Caribe hacia el resto del mundo. El término como tal es africano adscrito a la lengua palenquera, es una palabra compuesta por un prefijo cha y un sufijo mgpeta, el prefijo cha en lengua palenquera significa viejo, usted recuerda que nosotros decimos cha coma, chalole y cundo es niña decimos ña y el sufijo mpeta significa pedacito mpito; un mgpitoyuka, un mgpitokaña, en lengua palenquera. Entonces es una palabra compuesta entre algo viejo y un pedazo de algo, en este sentido es el cuchillo viejo y ¿de dónde surge ese cuchillo?, del proceso siguiente:

se compra el machete también conocido como rula, la rula en su tiempo de uso pasa a Soco que también es una palabra africana, de soco pasa a Chambelón y en ese mismo desgaste termina en Champeta que es lo último de ese machete o de esa rula. Ese desgaste de esa rula a medida que pasa el tiempo tiene un uso y el cuchillo que es la champeta es uno de los últimos usos que se le da, que termina en la cocina. Ese pedazo de cuchillo viejo que viene de un machete es champeta, allí está la expresión cha: viejo y mpeta: pedazo de una rula (...). Manuel Hernández (como se citó en Martínez, 2003, p. 26).
} 
mercado de Bazurto. Música de champeta no se diferencia mucho a la idea de música de plancha: lo que oyen las clases populares mientras hacen sus quehaceres. Pero también se refiere a los que andan armados. El champetúo era entonces el que usaba este mismo cuchillo para formar una pelea sangrienta en los bailes de picó. La asociación entre picós y violencia fue inmediata y, por transitividad, la asociación entre sus asistentes mayoría negros, con la violencia, forjándose un imaginario racial que pervive. Cohen (1995) observaba como "a través de la música se generan estereotipos que diferencian a la gente social y étnicamente, y se erigen barreras que distinguen a unos y otros" (p. 436). Así, en Cartagena, a través de la música que escuchan los unos se definen dentro de una normalidad aceptable y los otros son marcados como champetúos.

Esta carga simbólica ha calado más allá de las divisiones por estratos sociales y mucha gente de los barrios populares comparte la imagen del champetúo violento, especialmente la gente mayor. Así, dentro de los picós, el de champeta es el de peor fama. Los jóvenes del dansal a través de la tecnología y de sus formas de insertarse en el mundo globalizado que hace que su música suene en emisoras como La Mega con un público de estratos 3, 4 y 5, han logrado quitarse en un buen grado este estigma. Sin embargo, ir a la fiesta de picó, aún si es de dansal, sigue siendo algo prohibido, peligroso y denigrante. Estas fiestas "cuestionan claramente la identidad de una clase popular "respetable" y las normas que la sostienen. Y al mismo tiempo se oponen a los valores de la élite" (Cunin, 2003a, p. 283) así que el peligro no es tanto salir del picó apuñalado con champeta sino contaminarse de lo negro y caer en la tentación de disfrutar sin medida, sin orden, transgrediendo el lugar asignado.

Por supuesto, así como los matices de resistencia que tiene el universo picotero no son generados de forma consciente, tampoco lo son los motivos de rechazo por parte de sus opositores. La preocupación por estos ritmos y su constante rechazo se explica en que la música popular es un medio a través del cual se legitiman un orden social y una ideología. Así, la música ha sido históricamente utilizada para perpetuar relaciones de dominación (Connel \& Gibson, 2003). "Puede entonces decirse que la música posee una dualidad de estructura: como medio y el resultado de la experiencia, sirve para producir y reproducir sistemas sociales" (Kong, 1995, p. 185) ${ }^{34}$. Por esto la incomodad que generan los picos excede el campo de los gustos y se sitúa en el hecho de que su música incluye a gran parte de los excluidos, permitiéndoles, a través del ejercicio estético, empoderarse.

\footnotetext{
34 "Music can thus be said to possess a duality of structure: as both the medium and the outcome of experience, it serves to produce and reproduce social systems" (Kong, 1995, p. 185).
} 
Cuando a través de los picós lo ajeno se avecina con tanta fuerza, el desafío es contra el sistema social que se intenta reproducir proponiendo otra forma de producción simbólica. Frente a esto, los que se sienten amenazados generan una serie de imaginarios y estigmas para defenderse.

Esto ha hecho que los picoteros se sientan cada vez más perseguidos, aun cuando en Cartagena todavía hay público suficiente para organizar fiestas que convocan miles de personas. Pacho Manjón, dueño del picó El Conde, me habla con agotamiento del tema. "La relación con las autoridades es cada vez más compleja, los permisos son difíciles de conseguir y hay cada vez menos lugares donde se pueda montar un evento" (Francisco Manjón, comunicación personal, 19/04/2010). DJ Dever dice que mantiene al Passa-passa pequeño, a pesar de su fama, porque no cree que valga la pena invertirle a una máquina grande cuando cada vez son más fuertes las regulaciones que no los dejan tocar. Luis Mosquera, alias "Boleo", organizador de eventos explica:

Cuando ya nos otorgan el permiso, cuando llegan los requisitos, entonces que de pronto el comandante de policía que le toque de pronto la zona o algo así no quiere. Y pasa por encima de la autoridad de la secretaria del interior y dice aquí no hay baile porque yo no quiero, porque aquí hay situaciones de orden público y tal. Se inventa cualquier tipo de cosa, y le suspende el evento a uno (...) De pronto hay persona que no le gusta la música alto volumen, que es lo que es el picó (...). Entonces, no solamente que van a decir -no, miren que este picó suena muy duro, a mí no me gusta que esté ahí-, sino que se inventan otro tipo de situaciones como que hay una pelea, que hubo un muerto, que hay una machetera (...), y entonces hay otros que van mucho más allá se dedican a enviar cartas a los organismos de control, como personería, procuraduría y todo eso. (Luis Mosquera Gómez, comunicación personal, 15/04/10)

Niber García, DJ del Sabor Estéreo, cuenta cómo se fue acabando el picó porque cada vez se hacía más difícil hacer un baile cuando restringieron el toque en las calles de los barrios. Su público no podía ir detrás del picó a las zonas permitidas, además no conseguían pagar los costos elevados de los permisos requeridos. ${ }^{35}$ Estos permisos no son muy distintos a los que se requieren para cualquier evento masivo. Pero Anuar Peralta, DJ de El Demoledor, un picó pequeño, me explica que sacar los permisos no sólo es engorroso sino que es demasiado caro para ellos.

\footnotetext{
${ }^{35}$ Entrevista Niber García. Monumento India Catalina. 13/04/2010.
} 
Esto es para gozarla uno por acá. Lastimosamente es champeta y la champeta dicen que trae bandido, pero hay personas serias que también les gusta eso. Es algo que uno lo lleva en la sangre (...) pero no nos podemos poner al nivel del Rey y de otros picó que toque, y si usted lo buscó y si se lo apagaron, de malas, pero él se gana su plata. Aquí no, aquí usted puede quedar con toda la cerveza y el hielo y se perdió ese negocio. (Integrantes de El Demoledor, comunicación personal, 06/14/10)

Un picó pequeño gana a través de venta de cerveza. A este tipo de toques lo llaman "cervecero" porque no cobran boleta. Como no tienen el monto que cuesta los permisos, ni un organizador de eventos que invierta en ellos, se arriesgan muchas veces a tocar ilegalmente. Si llega la policía les hace apagar el equipo, se acaba la fiesta y pierden sin remedio el dinero que invirtieron.

Sorpresivamente, la que menos me habló de la violencia fue Nancy, funcionaria de la Secretaría del Interior, quien, además de explicar los requerimientos burocráticos, confesó:

Viendo las noticias y viendo las cosas de los disturbios en Cartagena, propiamente es más sicariato que disturbios en los picós (...), yo soy delegada y yo voy a los espectáculos (...) y hasta donde yo he ido a las 10 o 11 de la noche no se ha presentado ningún inconveniente (...), y tenía de pronto una mentalidad o una manera de pensar diferente a lo que era el espectáculo, y también con la champeta (...) porque si tú vas a ciertos lugares y tú vas a un baile de champeta tú lo gozas. Tú te gozas la música si te gusta la champeta y gozas el baile. (Nancy, comunicación personal, 13/05/10)

Es esto lo que sucede cuando uno comienza a entender de qué se tratan las fiestas de picó. Lejos están del imaginario de que la gente va a drogarse, emborracharse y pelear. Peleas hay, yo misma presencié algunas, pero no más de las hay en cualquier evento donde se consume alcohol. Se trata más bien de un lugar de esparcimiento y catarsis a través del baile y de la euforia, que además tiene unas características culturales muy complejas y devela muchas cosas de una ciudad tan sistemáticamente segregadora.

Aníbal Quijano, confiesa en el prefacio del libro de Quintero su experiencia al entregarse a la fiesta: “(...) no me había permitido entrar entero, corporalmente, al escondido espacio donde el poder y las gentes se juegan la vida cada día. Porque el ritmo era, exactamente, eso: un espaciotiempo de confrontación entre el poder y la corporeidad" Quijano (como se citó en Quintero, 2009, p. 34). Así, en este mismo proceso difícil de explicar del todo de forma racional, los champetúos cada noche de fiesta se juegan el orden simbólico de su mundo, lo reafirman, lo recrean y lo reinventan. He ahí la centralidad de la fiesta de picó. 
Meintjes (2004) en su escrito sobre el baile Nogma de los zulús, explica cómo este tipo de danza es una de las pocas fuentes de empoderamiento en un espacio donde las posibilidades de agencia, de lograr respeto y reconocimiento social son pocas. Dentro del Nogma, como poder creativo, las marcadas expresiones de masculinidad tienen a veces terribles consecuencias, entre ellas enfrentamientos violentos. Así el empoderamiento a través de la corporalidad contiene los principios del Eros y el Tánatos, de lo creativo y lo destructivo resumido en un ejercicio estético sublime, en el que por cierto, el golpe, Isigqi, es algo dominante, es lo que “¡Tiene el poder!".

Las similitudes son enormes con lo que sucede en un picó, sin ser conscientemente una danza ritual, pero tal vez sí heredera de estas características en las que el golpe, el meke, es lo dominante y lo que tiene el poder del ritmo, de la canción y de la máquina. Cuando los hombres pelean la mayoría de veces se debe a que les ofenden su poder masculino coqueteándole a alguna de las mujeres que los acompaña o rompiéndoles la botella de trago, símbolo de estatus (brindar alcohol para otros asistentes da reconocimiento afianza vínculos sociales y habla sobre el poder adquisitivo). El picó y bailar allí como si se jugaran las vidas es una forma de empoderamiento: ubicarse en un círculo de socialización y tener una identidad que incluso tiene tientes de resistencia, de reconocerse como algo criticado con pleno orgullo traducido en goce.

\section{Conclusiones}

Muchos han sido los factores que han configurado el espacio cartagenero, entendiendo el espacio como una construcción social atravesada por relaciones políticas y culturales desiguales (Leyshon et al., 1995; Cohen, 1995; Small, 1999; DeNora, 2004; Stokes, 2004; Krims, 2007). Pero en estas disputas geográficas la música y su inseparable aliado, el baile, han tenido una influencia poderosa. En Cartagena coexisten diferentes espacios sonoros que funcionan como instrumento para delimitar lugares. Estos lugares no solo son geográficos sino también psicológicos y emocionales y capaces de definir una concepción de mundo.

Específicamente, a través del sonido, el universo picotero ha logrado construir una espacialidad alterna a la comercial, y un sentido de localidad muy particular, eternamente imbricado con una globalidad alternativa en resonancia con la diáspora africana, con el que se identifican muchas de las personas excluidas por la Cartagena turística. El picó se ha configurado como un lugar que, a través de la "invasión" sonora que generan sus máquinas, entra en conflicto con la espacialidad aceptada que la élite 
cartagenera quisiera imponer: un espacio de tranquilidad donde la música (y la fiesta) se encuentra localizada en las discotecas de Getsemaní y en los grupos vallenatos y de gaitas representantes del folclor caribeño.

En Cartagena, los picós se asocian con clase y tácitamente con raza. Esto porque los capitales simbólicos musicales tienen la capacidad de perpetuar desigualdades tanto económicas como étnicas, raciales o de género (Pardo, 2009). Como dice DeNora (2004): “La música es mucho más que un arte decorativo; es un medio poderoso de orden social" (p. 163) Por eso la polémica alrededor de la champeta y su vehículo el picó no es solo una cuestión de gustos sino una lucha de poder reflejada en la distribución y en el entendimiento de lo espacial. Cuando los champetúos consiguen subvertir esas lógicas son víctimas de estigmas sociales.

A pesar de la carga simbólica que implica reconocerse como champetúo, son muchos los que se identifican no solo con la música sino con un estilo de vida. Esto se debe en gran parte a que los asistentes a una fiesta de picó encuentran en el lugar unos núcleos que los reconocen plenamente en contraste con lo poco que les ofrece la ciudadanía formal. Los picós funcionan como centros de socialización e incluso como lugares de reivindicación étnica. Así, el picó se configura como un lugar de identidad donde convergen una serie de procesos de creación, reinvención e intervención dando paso a una completa actuación musical en que se afianzan los lazos sociales.

Este paisaje sonoro, pegamento social y definitorio de un lugar de identidad es corporeizado a través del baile. Es en la fiesta donde tienen lugar una serie de ejercicios estéticos que construyen y reafirman una corporalidad cargada de valores y nociones de mundo. Estas propiedades tienen alcances más allá del evento festivo. La fiesta de picó se ve reflejada en la vida cotidiana de los asistentes cuyos cuerpos educados a través de los movimientos del baile, hablan sobre su condición como individuos y agentes dentro de la sociedad y espacialidad cartagenera.

En el universo picotero, cada elemento está pensado para generar un frenesí, llevarlos a "espelucarse". Esto significa que se entreguen al baile, a la experiencia sensual, dejando a un lado la mente y la compostura para entrar en estados extáticos que posibilitan una catarsis social, así como una reafirmación de valores alternativos llamados "desordenados" por los guardianes de la normalidad hegemónica. Pero es precisamente en el desorden inherente de esta música y su forma de bailarla donde radica su poder de transgresión. Los movimientos de estas danzas generan una

\footnotetext{
${ }^{36}$ "Music is much more than a decorative art; that it is a powerful medium of social order. Conceived in this way, and documented through empirical research, music's presence is clearly political, in every sense that the political can be conceived".
} 
visibilidad que puede ser tanto criticada como tentadora y, al mismo tiempo, celebran el derrumbamiento temporal del orden binario establecido.

Pero la tensión más evidente entre los opositores al picó y los champetúos estriba en la propiedad sonora de estas máquinas. Si consideramos que "el sonido es un elemento crucial en el mundo que construimos para nosotros mismos, y en el mundo que otros nos imponen" (Connel \& Gibson, 2003, p. 279) ${ }^{37}$, entendemos por qué las disputas en torno de los picós son centrales para la definición de la ciudad. A pesar de los esfuerzos de la dirigencia cartagenera y de los planes comerciales excluyentes, el universo picotero ha logrado configurar un paisaje sonoro particular difícil de contener. A la potencia amplificadora de las máquinas que lleva el sonido más allá de las barreras simbólicas y físicas, debemos sumarle la propiedad móvil de estas: una fiesta de picó puede organizarse en cualquier calle de la ciudad, club, salón comunal o discoteca. Y la música tiene mucho que ver con la definición de un lugar, un territorio e incluso un espacio, así los picós consiguen una reivindicación espacial, una reapropiación áurica de la geografía de la ciudad.

Aunque los champetúos no consideran su expresión popular como una resistencia, las características transgresoras de los ideales reproducidos en estas fiestas se enfrentan contra el orden espacial, simbólico y social pretendido. La música a gran volumen y la visibilidad de sus danzas sacan a los champetúos del anonimato calculado en el que la marginalidad de la Cartagena de postal los tiene relegados. Así, el picó da voz a muchos reprimidos y "la transgresión toma la forma de una fiesta, una manifestación ritual de ciudadanía" (Quintero, 2009, p. 50).

Sin embargo, estos matices subversivos (Cunin, 2003a; Bohórquez, 2000; Contreras, 2002; Muñoz, 2002) no pueden leerse desde un afrocentrismo que remite a un esencialismo sexual, así como tampoco se deben reíficar unos valores emancipatorios que tergiversen la compleja realidad del universo picotero. Como afirma Wade (1997b):

Es importante apreciar procesos de Resistencia y conflicto al tratar de comprender la política de la cultura, pero deseo distanciarme de un planteamiento que implícitamente opone unas élites homogenizantes contra otros subalternos heterogeneizantes y que interpreta las expresiones culturales como simples representaciones de estas posiciones sociales. (p. 87)

\footnotetext{
37 "Music is by nature geographical. Musical phrases have movement and direction, as though there are places in the music: quiet places and noisy places, places that offer familiarity, nostalgia or a sense of difference, while the dynamism of music reflects changing lives. Sound is a crucial element in the world we construct for ourselves, and the world that others construct and impose on us".
} 
De hecho, la relación de la champeta, y de los picós en general, con el entorno cartagenero es paradójica. Se debate continuamente entre el rechazo y la seducción, se opone a ciertas lógicas del sistema dominante pero al mismo tiempo necesita este, y de hecho, quiere hacer parte activa y visible en términos económicos. El universo picotero busca constantemente un reconocimiento y se preocupa por la estigmatización que ha sido efectiva para desplazar y reducir los espacios como una de las estrategias más efectivas para acabar con la fiesta. De hecho, desde que se realizó este trabajo de campo, las restricciones a los picós han aumentado y los espacios para los toques se han reducido.

Tal vez la forma más efectiva para que los picós como lugares de manifestación estética puedan permanecer se encuentra en empezar por hacer efectiva una democracia cultural en la que los públicos, en este caso el champetúo, puedan hacer parte de la toma de decisiones y se busquen políticas que amplíen y no restrinjan la fiesta popular. Lo primero que debe exigirse para que paren los hostigamientos es desarticular el picó de la violencia, pedirles a las autoridades locales que hagan a un lado la visión facilista que culpa al picó de todos los males de la ciudad, desconociendo problemas sociales de fondo como lo son las crecientes bandas criminales de supuestos desmovilizados que proliferan sembrando escuelas deniños sicarios por los sectores más vulnerables de la ciudad. Seguramente si se prohibieran por completo los bailes picoteros la violencia aumentaría en vez de disminuir. No es una coincidencia que los sectores que tienen menos acceso al entretenimiento sean los más violentos (Pérez y Salazar, 2007), y el picó es de los pocos lugares que tiene la propiedad de movilizarse por zonas donde no existen espacios de esparcimiento dando acceso a los excluidos. Además, antes de seguir apoyando la erradicación de los picós es preciso detenerse a observar la cantidad de ingresos que generan este tipo de fiestas para familias sin muchas más opciones laborales que sin ellos se sumarian a las ya escandalosas cifras de pobreza.

Si la fiesta de picó tiene tanta centralidad en la vida de la gente de las clases populares cartageneras es porque más allá de ser una verdadera fiesta que invita a entregarse completamente al disfrute, alrededor del picó se da una producción sensual de lugar, una forma de expresión cultural y un sistema económico. Asimismo, es un medio para reinventar unas tradiciones populares afrosincréticas que resaltan una serie de valores corporales estrechamente relacionados con un modo epistemológico de comprender el mundo, en el que música y baile, cuerpo y mente, rito y fiesta, no se encuentran disociados. Al final, dentro del musicar de la fiesta de picó se representan y reproducen las relaciones ideales del mundo que los rodea: es una forma de entretenimiento a la que tienen acceso, es incluyente en una ciudad segregadora, visibiliza a los sistemáticamente invisibilizados, los legitima como miembros de una sociedad que reproduce 
sus mismas lógicas, refuerza una estética, reafirma su corporeidad y les permite expresarse fuera de los ojos inquisidores de la Cartagena de postal.

\section{Referencias bibliográficas}

Bakhtin, M. (1993). A cultura popular na Idade Média e no Renascimento: o contexto de François Rabelais. São Paulo, Brasil: HUCITEC, Brasília: Editorial da Universidade de Brasília.

Biddle, I. \& Nights, V. (2007). Music National Identity and the politics of location. Hampshire: Ashgate. Birembaum, M. (2005). Acerca de una estética popular en la música y la cultura de la champeta en Colombia y el Caribe. Barranquilla, Colombia: Ediciones Uninorte.

Bohórquez, L. (2000). La champeta en Cartagena de Indias: Terapia musical popular de una resistencia cultural. Recuperado de http://www.hist.puc.cl/historia/iaspmla.html

Botero, C., Ochoa, A.M. y Pardo, M. (2011). Economías informales en la música de las ciudades de Cartagena, Barranquilla y Santa Marta en Colombia. Rio de Janeiro, Brasil: Fundación Getulio Vargas, IRDC-CDRI, Colegio mayor de Nuestra Señora del Rosario Brasil.

Carman, M., Viera, N. y Segura, R. (2013). Introducción. Antropología, diferencia y segregación urbana. En M. Carman, V. Neiva y R. Segura (coords.) Segregación y diferencia en la ciudad (pp. 11-34). Quito, Ecuador: FLACSO.

Cohen, S. (1995). Sounding out the City: Music and the Sensuous Production of Place. Transactions of the Institute of British Geographers, New Series, 20(4), 434-446. Recuperado de http://www.jstor.org/stable/622974.

Contreras, N.R. (2008). La cultura picotera: continuidad de la herencia Africana en el alma de las fiestas populares del Gran Caribe. Huellas. Revista de la Universidad del Norte, (80), 81-82. Recuperado de http://www.uninorte.edu.co/publicaciones/huellas.asp.

Contreras, N.R. (2002). Champeta/ terapia: un pretexto para revisitar las ciudadanías culturales en el gran Caribe. Ponencia presentada en el Foro Champeta, vida y ser de Cartagena. Universidad de Cartagena, Cartagena, Colombia.

Connel, J. \& Gibson, Ch. (2003). Sound Tracks. Popular music, identity and place. London and New York: Routledge.

Cunin, E. (2003a). Identidades a flor de piel. Lo "negro" entre apariencias y pertenencias: mestizaje y categorías raciales en Cartagena (Colombia). Bogotá, Colombia: IFEA-ICANH-UniandesObservatorio del Caribe Colombiano.

Cunin, E. (2003b). Identificação territorial, identificação étnica em Cartagena, Colômbia. Estudos Afro-Asiáticos, 25, 123-143.

Cunin, E. (2007). De Kinshasa a Cartagena, pasando por París: itinerarios de una música negra, la champeta. Aguaita, (15-16), 176-192.

DeNora, T. (2004). Music in everyday life. Cambridge: Cambridge University Press.

Gilroy, P. (2001). O Atlântico Negro. São Paulo, Brasil: Editora 34.

Hall, S. (1996). Identidad cultural y diáspora. En S. Castro-Gómez., O. Guardiola-Rivera. y C. Millán de Benavides. (Eds.), Pensar (en) los intersticios. Teoría y práctica de la crítica poscolonial (pp. 349 - 361 ). Bogotá, Colombia: Centro Editorial Javeriano (CEJA), Instituto de Estudios Sociales y Culturales (PENSAR), Pontificia Universidad Javeriana.

Hudson, R. (2006). Regions and place: music, identity and place. Progress in Human Geography, $30(5), 626-634$.

Kong, L. (1995). Popular music in geographical analyses. Progress in Human Geography, 19(2), 183-198. DOI: $10.1177 / 030913259501900202$.

Krims, A. (2007). Music and Urban Geography. New York, London: Routledge.

Larkin, B. (2004). Degraded images, distorted sounds: Nigerian Video and the infrastructure of piracy. Public Culture, 16(2), 289-314. 
Lemos, R. y Castro, O. (2008). The paraense technobrega Open Bussiness Model. Centro de Tecnologia e Sociedade da FGV DIREITO RIO, Supported by International Developement Research Centre (IDRC). Río de Janeiro, Brasil: Aeroplano editor.

Leyshon, A., Matless, D. \& Revill, G. (1995). The Place of Music. Transactions of the Institute of British Geographers, New Series, 20(4), 423-433.

Lock, M. \& Farquhar, J. (2007). Beyond the body proper. Reading the anthropology of material life. Durham and London: Duke University Press.

Martínez, L.G. (2003). La champeta: una forma de resistencia palenquera a las dinámicas de exclusión sociorraciales y culturales, puestas en marcha por las elites "blancas" de Cartagena y Barranquilla entre 1960 y 2000. Bogotá, Colombia: Universidad de los Andes.

Meintjes, L. (2004). Shoot the Seargent, shatter the mountain, the production of masculinity in Zulu Ngoma Song and dance in post-apartheid South Africa. Ethnomusicology Forum, 13(2), 173-210.

Mosquera, C. y Provansal, M. (2000). Construcción de identidad caribeña popular en Cartagena de Indias a través de la música y el baile de champeta. Revista Aguaita, (3), 98-114.

Muñoz, L.E. (2002). La música popular: Bailes y estigmas sociales. La champeta, la verdad en el cuerpo. Huellas. Revista de la Universidad del Norte, (67-68), 1-112.

Nash, C. (2000). Performativity in practice: some recent work in cultural geography. Progress in Human Geography, 24(4), 653-664. DOI: 10.1191/030913200701540654.

Ochoa, A.M. y Botero, C. (2007). Prácticas de circulación sonora en las músicas de fusión y anarkopunk en Bogotá y Medellín. [Inédito].

Paccini, D. (1993). The picó phenómenon in Cartagena, Colombia. Revista América Negra, (6), 69-115.

Pardo, M. (2009). Música y sociedad en Colombia. Translaciones, legitimaciones e identificaciones. Bogotá, Colombia: Editorial Universidad del Rosario.

Pardo, M. (2010). Entre el espectáculo y la agencia. Signos afrodescendientes y políticas públicas en Cartagena. En F. Ávila Domínguez., R. Pérez Montfort. y Ch. Rinaudo. (Eds.), Circulaciones culturales. Lo afrocaribeño entre Cartagena, Veracruz, y La Habana (pp. 69 - 94 ). México D.F., México: CIESAS-IRD-Universidad de Cartagena-AFRODESC.

Pérez, G.J. y Salazar, I. (2007). La pobreza en Cartagena: Un análisis por barrios. Recuperado de http://www.banrep.gov.co/publicaciones/pub_ec_reg4.htm

Quintero, Á. (2009). Cuerpo y cultura: las músicas "mulatas" y la subversión del baile. Mad rid, España: \&nexos y diferencias.

Samuels, D. W., Meintjes, L., Ochoa, A. M. \& Porcello, T. (2010). Soundscapes: Toward a sounded anthropology. Annual Review of Anthropology, 39, 329-345. DOI: 10.1146/ annurev-anthro-022510-132230.

Small, C. (1999). El musicar: un ritual en el espacio social. Trans. Recuperado de www.sibetrans. com/trans/trans4/small.htm.

Stallybrass, P. \& White, A. (1986). The Politics and Poetics of Transgression. Nueva York: Cornell University Press, Ithaca.

Stokes, M. (2004). Music and the global order. Annual Review of Anthropology, (33), 47-72. DOI: 10.1146/annurev.anthro.33.070203.143916.

Straw, W. (1991). Systems of articulation, logics of change: communities and scenes in popular music. Cultural Studies, Vol. 5, no. 3. 368 - 388

Straw, W. (2002). Scenes and sensibilities. Public, (22-23), 245-257.

Wade, P. (1997a). Gente negra, nación mestiza. Dinámicas de las identidades raciales en Colombia. Bogotá, Colombia: Editorial Universidad de Antioquia-ICAN-Siglo del Hombre Editores-Ediciones Uniandes.

Wade, P. (1997b). Entre la homogeneidad y la diversidad: la identidad nacional y la música costeña en Colombia. En M.V. Uribe y E. Restrepo. (Eds.), Antropología en la modernidad (pp. 61-91). Bogotá, Colombia: ICANH - Colcultura.

Wade, P. (2009). Música y sociedad en Colombia. Translaciones, legitimaciones e identificaciones. Bogotá, Colombia: Editorial Universidad del Rosario. 